\title{
MARCO CONCEPTUAL PARA INVESTIGACIONES TSUNAMIGÉNICAS: CASO LITORAL PACÍFICO COLOMBIANO
}

\author{
Erick R. Velasco'; Gloria I. López²
}

DOI: http://dx.doi.org/10.18273/revbol.v38n4-2016005 (c) (1)

Forma de citar: Velasco, E.R., y López, G.I. 2016. Marco conceptual para investigaciones tsunamigénicas: caso litoral Pacífico colombiano. Boletín de Geología, 38(4): 79-106.

\section{RESUMEN}

A nivel histórico, la Costa Pacífica Colombiana ha presenciado seis tsunamis en los últimos 130 años, de los cuales dos han ocasionado completa destrucción de algunos municipios y provocado víctimas humanas. El presente trabajo pretende dar las bases conceptuales necesarias para abordar investigaciones focalizadas a la caracterización de la amenaza por tsunami, verificar el estado del arte y determinar las necesidades investigativas futuras. Toda adecuada realización de investigaciones en paleo-tsunamis debe ser multi-disciplinaria, y compilar, obtener y analizar información geológica, geomorfológica, biológica, antropológica, arqueológica e histórica, lo más detallada posible. Hasta el momento en Colombia, los trabajos realizados en torno a tsunamis han estado enfocados a la cuantificación de la inundación en localidades como Tumaco y Buenaventura. No obstante, a lo largo de la Costa Pacífica Colombiana aún no se ha trabajado en la identificación y caracterización de las fuentes de tsunami, búsqueda y caracterización de evidencias físicas de eventos pasados (e.g. depósitos de paleo-tsunamis), microzonificación sísmica regional, cambios en patrones de vegetación por eventos extremos o el impacto a la dinámica de comunidades indígenas antiguas por tsunamis, entre otros. Para que la gestión del riesgo sea efectiva, deben generarse mapas de amenaza por tsunami que integren todas las herramientas y disciplinas que identifiquen y caractericen dicha amenaza. Por ende, aquí se proponen los pasos a seguir para adecuadas investigaciones tsunamigénicas.

Palabras clave: paleo-tsunamis, depósitos de tsunamis, paleo-sismología, Pacífico Colombiano, Zona de Subducción de Nazca.

\section{CONCEPTUAL FRAMEWORK FOR TSUNAMIGENIC RESEARCH: COLOMBIAN PACIFIC COAST CASE STUDY}

\begin{abstract}
Historically, the Colombian Pacific Coast has witnessed six tsunamis in the past 130 years, two of which have caused complete community destruction and human loss. The present paper aims to provide a conceptual framework needed to approach palaeo-tsunami research in the area, verifying the state of the art of tsunami hazard characterization and identifying any future investigations. Any acceptable palaeo-tsunami investigation should be multi-disciplinary, and compile, acquire and analyze in much detail, geological, geomorphological, biological, anthropological, archaeological and historical information. So far, the only research done related to tsunami hazard has been for the coastal cities of Tumaco and Buenaventura, and it has been focused on quantification of tsunami flooding. However, no research has yet been done on the identification and characterization of tsunami sources, exploration and characterization of the physical evidence of past events (e.g. palaeo-tsunami deposits), seismic micro-zonation, regional changes in vegetation patterns resulting from extreme events, or changes related to indigenous peoples' habitational patterns or settlement abandonment, among others. For an effective risk management, tsunami hazard maps have to be emplaced, but they should integrate all the proxies and disciplines that enhance the identification and characterization of this hazard. We propose herein, the steps to follow to develop adequate tsunamigenic research.
\end{abstract}

Keywords: palaeo-tsunamis, tsunami Deposits, paleoseismology, Pacific Coast of Colombia, Nazca Subduction Zone.

${ }^{1}$ Universidad Nacional de Colombia, Facultad de Ciencias, Dpto. de Geociencias, Sede Bogotá, errvelascore@unal.edu.co

${ }^{2}$ Laboratorio de Dataciones por Luminiscencia, Centro Nacional de Investigación sobre la Evolución Humana (CENIEH).

Burgos, España, gloria.lopez@cenieh.es lopezgi.phd@gmail.com 


\section{INTRODUCCIÓN}

La necesidad de mejorar el conocimiento de ciertos fenómenos geológicos actuales en Colombia y de conocer a profundidad cuales de estos son amenazantes para la dinámica humana, hace indispensable la realización de estudios entorno a tsunamis. La conceptualización de un fenómeno como base de investigaciones profundas permite dimensionar el problema y conocer el punto de partida.

En este artículo, denominado marco conceptual, se quiere dar una mirada al cuadro geológico, biológico, antropológico/arqueológico e histórico de la Costa Pacífica Colombiana, como cimiento para las bases de próximos estudios tsunamigénicos en la zona. La intención de este artículo es dar a conocer los criterios base y conocimiento de fondo que se debieran compilar, entender, adquirir y analizar cuando se trata de hacer investigaciones sobre depósitos sedimentarios de tsunamis, o paleo-tsunamis, y sus objetivos primordiales: el establecimiento de intervalos de recurrencia de tsunamis, su extensión y magnitud, posible fuente, la comprobación de los modelos teóricos de inundación, para así finalmente generar mapas adecuados de amenaza y riesgo por tsunami. Estos a su vez serán la herramienta esencial (con finalidad social directa) para mejorar la implementación de planes locales, regionales y nacionales de prevención, mitigación y atención ante posibles tsunamis.

Los depósitos generados por la inundación provocada por tsunamis pueden preservarse tanto en zonas subaéreas costeras como en la plataforma continental somera (ambiente sub-marino), dependiendo de múltiples factores, como se explica más adelante. Los tsunamis son considerados procesos geológicos co-sísmicos secundarios, generadores de evidencia paleo-sísmica (McCalpin, 2009), ya que la gran mayoría de estos son provocados por grandes $(>\mathrm{Mw} 7)$ y súbitos movimientos tectónicos a lo largo de zonas de subducción. Sin embargo, tsunamis lejanos o transoceánicos también pueden generar evidencia geológica similar, por lo que el estudio de paleo-tsunamis no solo es de importancia para la región o país con amenaza sísmica local, sino también para todas aquellas regiones que circunden zonas tectónicamente activas (como el Cinturón de Fuego del Pacífico). El presente compendio de información, referencia ejemplo de método científico para investigaciones tsunamigénicas, se enfoca primordialmente en tsunamis generados por actividad sísmica, sin descartar la posibilidad de generación por otros procesos geológicos naturales (señalados más adelante).

Para entender la amenaza frente a tsunamis, es indispensable no solo desarrollar modelos conceptuales sobre el efecto de su inundación costera, si no y sobre todo, desarrollar investigación que analice las evidencias geológicas y físicas dejadas por los tsunamis a lo largo de la costa, además de todo lo que implica estar en proximidad a la zona de posible generación de tsunamis locales y sus efectos consecuentes (e.g. subsidencia del terreno evidenciado por la existencia de suelos enterrados provocados por sismos inter-placa a lo largo de una zona de subducción). En el Pacífico colombiano han ocurrido seis tsunamis históricos en los últimos 130 años, de los cuales se tenga registro, entre 1882 y 1979 (TABLA 1), sin que aún se hayan desarrollado investigaciones apropiadas de búsqueda de la evidencia física dejada por estos tsunamis a lo largo de la costa, ni mucho menos estudios que permitan encontrar tsunamis aún más antiguos, prehistóricos, ocurridos en tiempos geológicos previos. Es indispensable encontrar, identificar, ubicar y datar dicha evidencia paleo-tsunamigénica para así poder establecer la periodicidad de ocurrencia de tsunamis en el país.

Si bien el enfoque de este trabajo en particular se centra en el Pacífico colombiano, resaltando más la región sur nariñense debido a la cantidad (aunque efímera) de información multi-disciplinaria publicada y disponible, la metodología científica aquí propuesta puede ser aplicada al resto del litoral Pacífico, la región Caribe colombiana, e incluso otros países con riesgo potencial por tsunamis. Aunque en el litoral Pacífico colombiano prima la amenaza sísmica por la cercanía a la zona de subducción de Nazca (FIGURA 1), la finalidad de este artículo no es la de proporcionar una compilación exhaustiva y detallada, ni mucho menos un análisis o discusión profunda del marco tectónico del Pacíico colombiano, que ya en sí es complejo y demanda mayor atención. Aquí lo que se hace es una compilación general de información sismo-tectónica que nos brinde las herramientas básicas para diferenciar potencialidad de evidencias co-sísmicas primarias (e.g. subsidencia, licuefacción) y/o secundarias (e.g. depósitos de tsunamis) en la región, para poder analizar de manera más racional los resultados obtenidos del procesamiento de datos y evidencia física encontrada en la región. 
TABLA 1. Sismos generadores de tsunamis históricos en el Pacífico colombiano, localizados entre $1^{\circ}$ y $7.5^{\circ}$ de latitud Norte (NGDC, 2015).

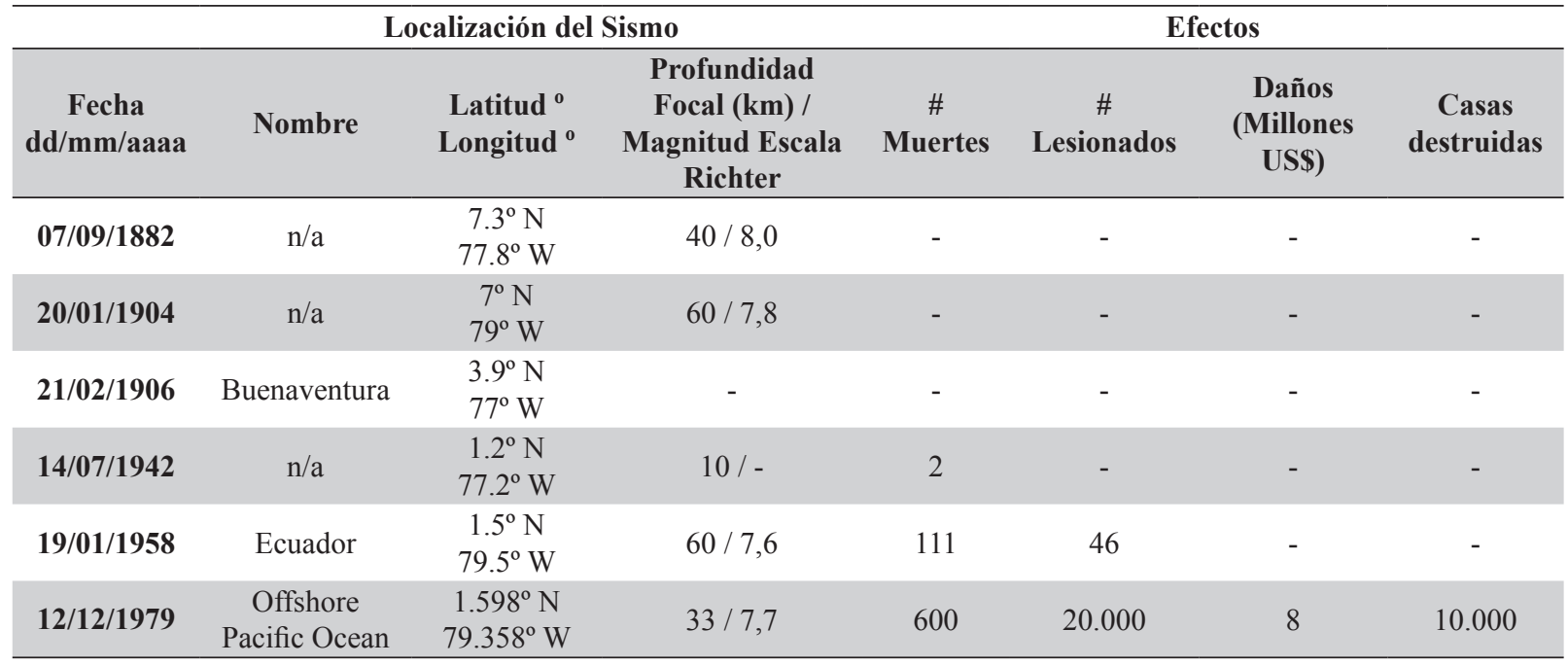

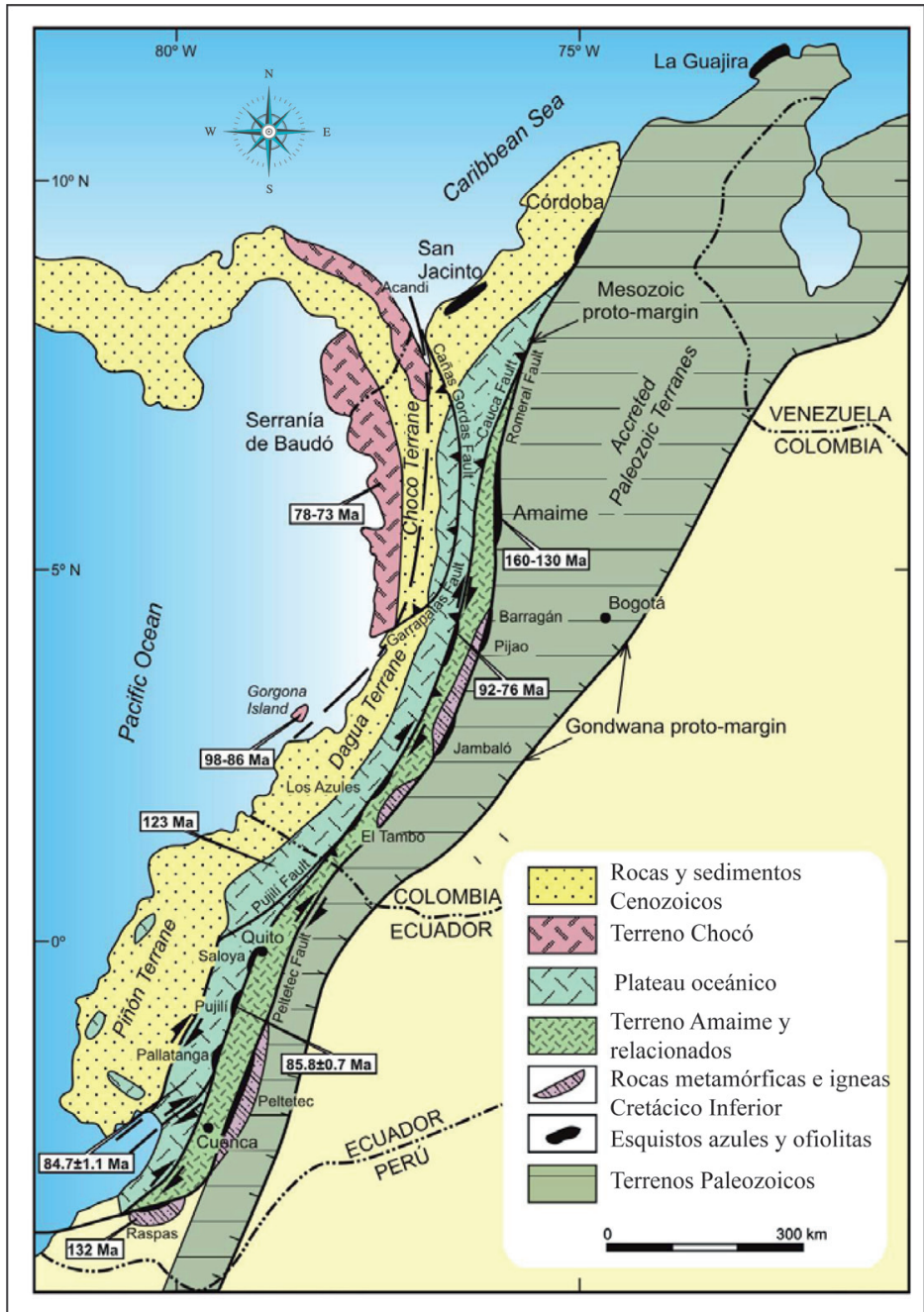

FIGURA 1. Configuración tectónica actual de Los Andes del Norte. Se observa la relación geológica entre las unidades de Colombia y Ecuador, mostrando la similitud tectónica en ambas zonas, característica importante en la cuantificación y limitación de la zona de probable fuente de amenaza local por tsunami (Modificado de Ramos, 2010). 


\section{LA IMPORTANCIA DE LA EVIDENCIA PALEO-TSUNAMIGÉNICA}

La palabra tsunami proviene del Japonés tsu (puerto o bahía) y nami (ola) (ITIC, 2015). Este evento natural ha sido definido como un movimiento temporal de onda generado por la perturbación súbita o desplazamiento vertical de un gran volumen de agua, ya sea en el océano o en cuencas (semi-) cerradas (Sugawara et al., 2008). La onda generada por un tsunami se propaga concéntricamente en la cuenca, a velocidades de hasta $800 \mathrm{~km} / \mathrm{h}$, casi imperceptibles en alta mar (rara vez $>1 \mathrm{~m}$ de altura y períodos de kilómetros de distancia). Cuando un tsunami llega a la costa, su velocidad disminuye (aún siendo superior a las de olas generadas por el viento), pero su amplitud se incrementa dramáticamente ya que su energía de flujo (la cual depende de su velocidad y altura) se mantiene casi constante. Por consiguiente, al entrar en aguas costeras más someras, la altura del tsunami crece progresivamente debido a la reducción de la profundidad, produciendo una pared de agua de hasta decenas o centenares de metros de alto, proporcional al volumen de agua desplazado en el punto de origen, que tiene que acomodarse al contexto espacial de la cuenca costera, con todas sus restricciones geomorfológicas, batimétricas, topográficas y geográficas (Sugawara et al., 2008). La ola resultante penetra cientos de kilómetros tierra adentro, inundando temporalmente la zona costera (hasta decenas de metros de altura), generando evidencias tanto geomorfológicas como sedimentarias, provocando así tanto erosión severa, como depositación y cambios geográficos en la línea de costa, sumados al gran impacto, daño severo y destrucción de la región afectada. Los tsunamis pueden ser clasificados como locales, regionales o lejanos, dependiendo de la distancia entre la costa afectada y la fuente (Farreras et al., 2005; Bryant, 2010). El impacto del tsunami en la costa, además de la magnitud del evento que lo generó, dependerá de la distancia a la fuente, de tal manera que a medida que las fuentes son más lejanas el impacto esperado es menor pues la energía de la ola se disipa con la distancia recorrida durante la propagación de la onda en la cuenca u océano.

Las fuentes tsunamigénicas se categorizan básicamente en cuatro fenómenos naturales de gran magnitud: sismos, deslizamientos, actividad volcánica, impacto de asteroides, y actividad antropogénica (e.g. explosiones atómicas) (Bryant, 2010). La investigación sobre tsunamis, tomado estrictamente como fenómeno geológico había sido realizada en otros países hasta hace unos 30 años desde el punto de vista sismológico, estudiando básicamente los fenómenos históricos y recientes, y la caracterización de la fuente sísmica a partir de modelos numéricos que mostraban la posible propagación de onda y las láminas de inundación resultantes (Shuto and Fujima, 2009). A partir de esa fecha, la investigación comenzó a fortalecerse por el inicio del estudio de la evidencia física dejada por tsunamis pasados, ya enterrados en el subsuelo (Bryant, 2010; Chagué-Goff et al., 2011; Goff et al., 2012: McCalpin, 2009). Este tipo de investigación se conoce como investigación de paleo-tsunamis, es decir el estudio de tsunamis ocurridos antes del registro histórico de los cuales no se tienen registros escritos y/o instrumentales (ITIC, 2015). Dicha disciplina, en primera instancia, hizo énfasis en el estudio de la evidencia física de origen geológico y paleontológico y en la identificación de elementos claves que aten el depósito con el fenómeno, para así poder ser identificado y diferenciado correctamente de otros eventos y productos de origen marino (Chagué-Goff et al., 2011; Goff et al., 2012; McCalpin, 2009). La implementación de ésta disciplina permite fortalecer los modelos numéricos y sismológicos propuestos ya que así se podrá determinar la frecuencia de ocurrencia (i.e. periodicidad o intervalo de recurrencia), pero también el alcance espacial y extensión reales del evento a lo largo de la zona costera, ríos y estuarios arriba, y tierra-adentro. Hasta el catastrófico tsunami de Indonesia del 2004, dichas investigaciones en paleo-tsunamis se habían concentrado en regiones costeras situadas en los hemisferios norte y sur, más que en las zonas inter-tropicales y/o zona ecuatorial, debido a un sin número de motivos, incluyendo (pero no solamente) motivacionales, financieros, recursos, intereses socio-económicos, concentraciones poblacionales, niveles de riesgo y vulnerabilidad, facilidades de acceso debido a la cobertura vegetal y/o clima, entre otros.

La esencia del estudio sobre los depósitos de paleotsunamis es su hallazgo, caracterización e identificación, y datación. Sin lo anterior no se podría comprobar determinantemente el riesgo ante el fenómeno de tsunamis. Sedimentológicamente éstos son muy diversos y complejos de diferenciar de otros fenómenos de origen marino (Morton et al., 2007; Chagué-Goff et al., 2011; Goff et al., 2012). Aunque existen características que comparten los depósitos en cada ambiente, éstos varían dependiendo de las características particulares del fenómeno, del ambiente sedimentario en sí y de la disponibilidad de material para acarrear en cada zona. En la FIGURA 2 se pueden observar algunos de los diferentes tipos de depósitos en función del ambiente 
sedimentario marginal, cuyos parámetros generales de identificación y caracterización se describen y compilan en la TABLA 2. En ciertos casos no queda otra evidencia más que superficies fuertemente erosionadas (Bryant, 2010; Shiki and Yamazaky, 2008; Macinnes et al., 2009; McCalpin, 2009).

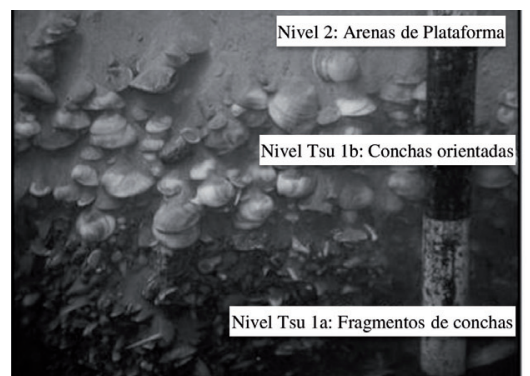

(a)

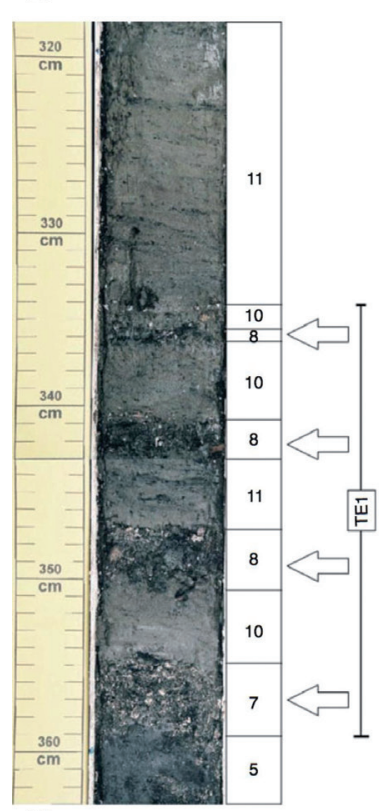

(d)

(e)

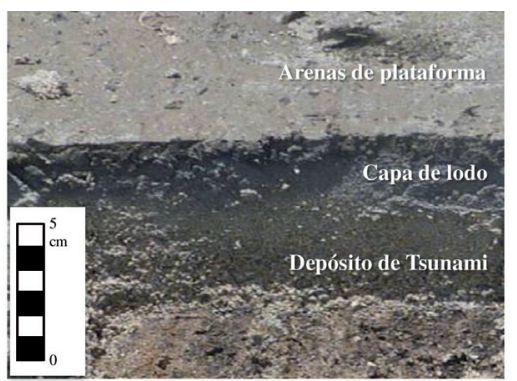

(b)

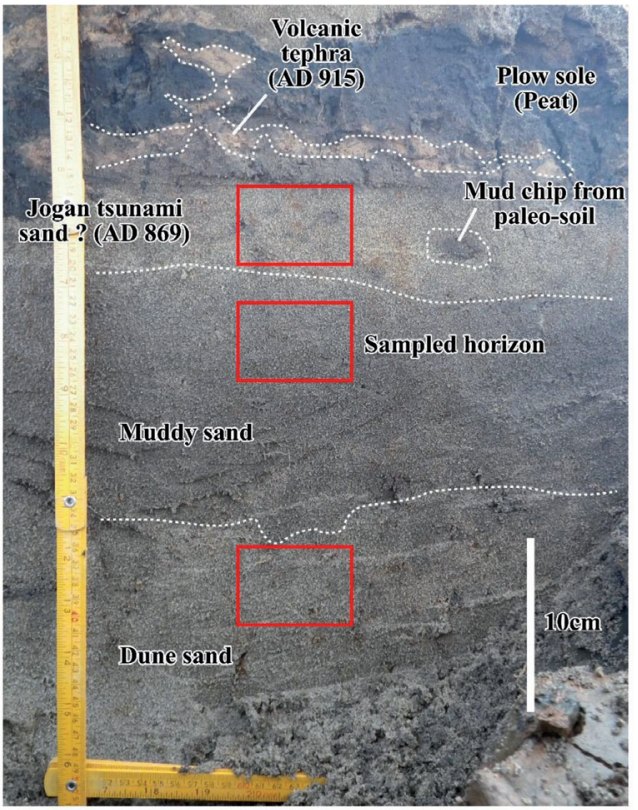

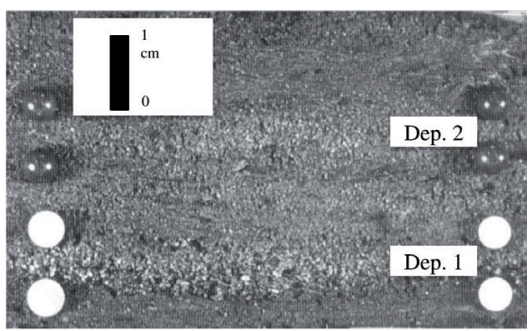

(c)

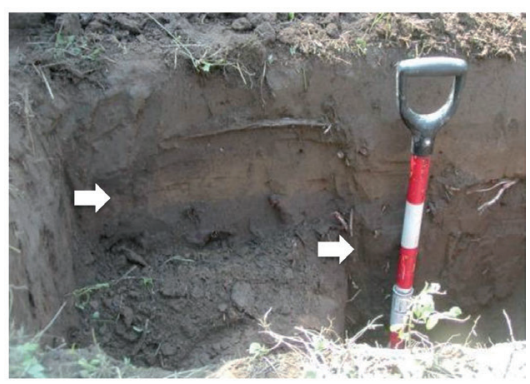

(f)

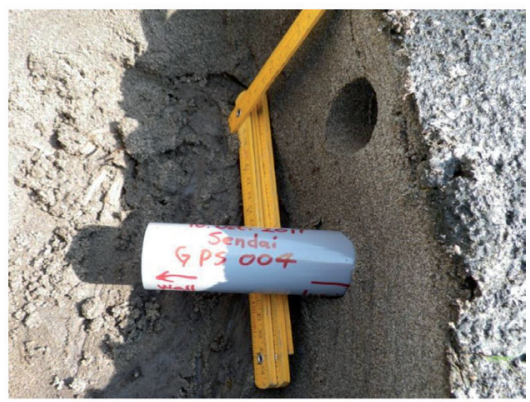

(g)

FIGURA 2. Ejemplos de diferentes unidades sedimentológicas de depósitos de tsunami en varios ambientes costeros: (a) Depósito de tsunami sumergido, preservado en la plataforma somera continental (profundidades de 15-20 m), frente a Caesarea Maritima, Costa Mediterránea Israelí: Nivel Tsu 1a: Fragmentos de conchas in situ, evidencia de penetración, retrabajamiento y energía del tsunami; Nivel Tsu 1b: Conchas enteras orientadas con su parte convexa hacia abajo, in situ, producto de la regresión de la inundación y decantación de material flotante; Nivel 2: Arena de plataforma somera, depositación marina de condiciones normales (c.f. Reinhardt et al., 2006); (b) "Depósito de tsunami grano-creciente hacia arriba (amarillo y gris), cubierto por una capa de lodo" (c.f. Chagué-Goff et al., 2011); (c) Dos depósitos de tsunami correspondientes a diferentes etapas de inundación del mismo evento. En ambos casos arenas grano-decrecientes hacia arriba (c.f. Clague et al., 2000); (d) Diferentes eventos de tsunami encontrados en el lago Kakawis, isla de Vancouver, Canadá. Unidades con pobre selección (señaladas por flechas), embebidas en sedimentos lacustres (c.f. López, 2012); (e) Playa Sendai, Japón: ejemplo de una sucesión estratigráfica de playa con litología y textura muy similares a primera vista, pero de orígenes diversos. Los recuadros rojos indican lugares de recolección de muestras para datación por OSL. Foto cortesía de Dr. Daisuke Sugawara (com. pers. a GIL 2011); (f) Trinchera en zona pantanosa inter-mareal del estuario de Ixtapa, México. Las flechas señalan 2 niveles de arena oxidada (1-2 cm de espesor para el inferior y 5-10 cm el superior) correspondientes a los tsunamis de 1979 y 1985 respectivamente, que afectaron la Costa Pacífica Mexicana (c.f. Ramírez-Herrera et al., 2012). Foto cortesía de Dr. María Teresa Ramírez-Herrera (com. pers. a GIL 2010); (g) Playa de Sendai, Japón, siete meses después del Gran Sismo y Tsunami de Tohoku del 11 de Marzo de 2011, con Mw 9,0 en la escala de Richter. El núcleo está siendo tomado para obtener una muestra para análisis por OSL (10 Octubre 2011). Es de anotar que el tsunami depositó un horizonte de textura bastante homogénea de sedimentos en su mayoría ferro-magnesianos de unos 10 a $50 \mathrm{~cm}$ de espesor en las zonas bajas de playa. Foto cortesía de Dr. Daisuke Sugawara (com. pers. a GIL 2011). 
TABLA 2. Algunas características sedimentológicas y paleontológicas de los depósitos de tsunami en diferentes ambientes costeros (recopilación y compendio según: López and Bobrowsky, 2001; Sugawara et al., 2008; Goff et al., 2012; López, 2012).

\begin{tabular}{|c|c|c|c|c|c|}
\hline \multirow[b]{2}{*}{ Características Sedimentológicas y Paleontológicas } & \multicolumn{5}{|c|}{ Ambiente Sedimentario } \\
\hline & Playas & $\begin{array}{l}\text { Lagunas } \\
\text { Costeras }\end{array}$ & $\begin{array}{c}\text { Zona } \\
\text { Intermareal }\end{array}$ & Estuarios & $\begin{array}{c}\text { Mar } \\
\text { Abierto }\end{array}$ \\
\hline $\begin{array}{l}\text { Capas en forma de cuña que disminuyen en espesor } \\
\text { costa adentro }\end{array}$ & $\mathrm{X}$ & $\mathrm{X}$ & $\mathrm{X}$ & $\mathrm{X}$ & \\
\hline $\begin{array}{l}\text { Detritos siliciclásticos provenientes de la plataforma } \\
\text { continental }\end{array}$ & $\mathrm{X}$ & $\mathrm{X}$ & $\mathrm{X}$ & $\mathrm{X}$ & $\mathrm{X}$ \\
\hline Gran variedad granulométrica y pobre selección & $\mathrm{X}$ & $\mathrm{X}$ & $\mathrm{X}$ & $\mathrm{X}$ & \\
\hline Grano-decrecimiento hacia arriba & $\mathrm{X}$ & $\mathrm{X}$ & $\mathrm{X}$ & $\mathrm{X}$ & $\mathrm{X}$ \\
\hline Depósitos embebidos en sedimentos típicos del ambiente & $\mathrm{X}$ & $\mathrm{X}$ & $\mathrm{X}$ & $\mathrm{X}$ & $\mathrm{X}$ \\
\hline Contacto inferior erosivo & $\mathrm{X}$ & $\mathrm{X}$ & $\mathrm{X}$ & $\mathrm{X}$ & \\
\hline $\begin{array}{l}\text { Macro- y micro-fauna marina en el segmento inferior del } \\
\text { depósito y macro- y micro-fauna continental en la parte } \\
\text { superior del depósito, producto de retro-lavado. Ambos } \\
\text { segmentos usualmente retrabajados }\end{array}$ & $\mathrm{X}$ & $\mathrm{X}$ & $X$ & $\mathrm{X}$ & \\
\hline $\begin{array}{l}\text { Turbas en la parte inferior producto de subsidencia } \\
\text { co-sísmica }\end{array}$ & & $\mathrm{X}$ & & & \\
\hline $\begin{array}{l}\text { Moluscos usualmente apilados en los bordes de los } \\
\text { cuerpos de agua, llegando a decenas de centímetros de } \\
\text { espesor }\end{array}$ & $\mathrm{X}$ & $\mathrm{X}$ & & & \\
\hline $\begin{array}{l}\text { Precipitación de carbonato micro-cristalino producto de } \\
\text { la introducción de aguas concentradas anómalas para el } \\
\text { ambiente }\end{array}$ & & & $X$ & & \\
\hline Fragmentos de plantas & $\mathrm{X}$ & $\mathrm{X}$ & $X$ & $\mathrm{X}$ & $X$ \\
\hline
\end{tabular}

Además de poder y deber ser caracterizados $\mathrm{y}$ diferenciados con base en la sedimentología, micropaleontología y geoquímica, entre otras herramientas, los sedimentos tsunamigénicos deben ser ubicados en el tiempo geológico por medio de la implementación de técnicas de datación radiométricas numéricas como la Luminiscencia Estimulada Ópticamente (OSL, por sus siglas en Inglés), lo cual permite conocer la edad de enterramiento del depósito de tsunami, que es inmediatamente posterior al evento de depositación (c.f. Reinhardt et al., 2006; Ramírez-Herrera et al., 2012; Prendergast et al., 2012) Igualmente pueden ser datados con radiocarbono $\left({ }^{14} \mathrm{C}\right)$ (López, 2012), pero debido a que este método utiliza material orgánico, éste pudo tener orígenes más antiguos que el momento de creación del depósito en sí, dificultándose la utilidad del método y precisión de la edad obtenida. Este método es sin duda muy aplicado, pero debe usarse con cautela en este tipo de depósitos caótico-catastróficos.

Dada la periodicidad de tsunamis en el mundo, ya que no es un fenómeno recurrente o común comparado con otros desastres naturales o procesos geológicos más frecuentes, el nivel de investigación y conocimiento es alto debido al grado de impacto, perjuicio y riesgo existentes (debido a la gran cantidad de bibliografía existente sobre depósitos de tsunamis en los hemisferios norte y sur, la aquí compilada es una pequeña, pero substancial muestra 
de este tipo de investigaciones). En América Latina es relativamente reciente la investigación sobre evidencias de paleo-tsunamis, teniendo más tradición en Chile (e.g. Lagos, 2000; Cisternas et al., 2005; Reinhardt et al., 2010). Poco a poco está surgiendo en Ecuador y México (Chunga y Quiñónez, 2013; Chunga and Toulkeridis, 2014; Contreras-López, 2014; Ramírez-Herrera, 2011; Ramírez-Herrera et al.; 2012, 2016), como también en regiones del oeste del Pacífico sur en las que se han encontrado evidencias de sismos tsunamigénicos suramericanos trans-oceánicos (e.g. Borrero and Goring, 2015). Sin embargo, aún es muy poco lo que se conoce sobre su generación, existencia de evidencia física, grado de preservación de ésta y periodicidad de este tipo de eventos en zonas ecuatoriales y tropicales del mundo, por lo que cualquier aporte científico que pueda generarse para estas zonas es de un valor inmensurable para la sociedad, comunidad científica y la investigación en paleo-tsunamis en general. Por otro lado, el tipo de evidencia y sedimento tsunamigénico varía según la región, e.g. Pacífico vs. Caribe, ya que depende directamente de la tipología sedimentaria de la cuenca donde se genera el tsunami, y por ende, si prevalece más su carácter siliciclástico o biogénico, determinando así el parámetro que más ayudará a su caracterización e identificación. Por ejemplo, a lo largo de la Costa Pacífica de Norte América se identificaron capas y niveles de arenas y gravas siliciclásticas de origen tsunamigénico (e.g. Atwater et al., 1995, 2005; López, 2012), mientras que en el Caribe, por ser región en la que prima material coralino y biogénico, la identificación se hace por caracterización exclusiva de macro y micro-fauna (e.g. Atwater et al., 2011; Pilarczyk and Reinhardt, 2011).

\section{PACÍFICO COLOMBIANO: MARCO TECTÓNICO, GEOLOGÍA Y GEOMORFOLOGÍA}

Al noroeste de la placa Suramericana se encuentran Los Andes colombianos, morfológicamente compuestos por tres grandes cadenas montañosas sub-lineales (Villagómez et al., 2011), limitados al oeste por la zona de subducción de la placa de Nazca (Taboada et al., 1998) (FIGURA 1), zona de interés en cuanto a generación de tsunamis, las cuales se extienden hacia el sur del continente. La configuración litológica tanto en Colombia como en Ecuador es similar, mostrando que procesos tectónicos y genéticos no son solamente actuales (FIGURA 1).
La subducción en Los Andes, en términos generales, presenta variaciones morfológicas de sur a norte, desde subducción plana en la parte central de Chile, Perú y el norte de Colombia ("flat slab"), hasta empinada en Bolivia, Ecuador y el sur de Colombia (Sun et al., 2015; Chiarabba et al., 2015) (FIGURA 3).

La subducción en Colombia es evidenciada por una fuerte sismicidad (Taboada et al., 1998; Vargas et al., 2011; Vargas and Mann, 2013; Chiarabba et al., 2015), con hipocentros alineados a los cordones cordilleranos que tienen profundidades entre 0 y $32 \mathrm{~km}$ en cercanías a la Costa Pacífica y piedemontes cordilleranos, y profundidades mayores de $120 \mathrm{~km}$ bajo las cordilleras Central y Occidental principalmente (Vargas and Mann, 2013).

En el Pacífico colombiano, la placa de Nazca presenta irregularidades morfológicas asociadas a montes submarinos de antiguos puntos calientes y suturas de dorsales (Meschede and Brackhausen, 2000); a las últimas le atribuyen cambios en la morfología de subducción, se propone que la subducente placa de Nazca se comporta de manera no homogénea en la trinchera colombiana; plantean la existencia de un "desgarre" este - oeste de la placa con una longitud aproximada de $240 \mathrm{~km}$ y ubicado en latitud $5^{\circ}$ Norte, llamado "Caldas Tear" (Vargas and Mann, 2013) o falla transformante de Coiba (CTF) (Chiarabba et al., 2015); éste separa una zona de subducción plana al norte de una zona de subducción inclinada al sur (ver FIGURA 3).

Por el contrario otros autores sugieren que la placa de Nazca subduce de forma homogénea a lo largo del Pacífico, bajo el bloque Chocó en la parte norte y finaliza abruptamente al sur de la serranía del Baudó, punto en el cual se superpone a la placa Caribe en subducción (Taboada et al., 2000)

Independientemente de las interpretaciones es innegable decir que las irregularidades de la corteza oceánica en el Pacífico afectan la dinámica de subducción (Husen et al., 2002; Kodaira et al., 2000; von Huene et al., 2012), aumentando o disminuyendo la velocidad de liberación de energía, modificando la morfología estructural y determinando el área de ruptura, entre otros factores, lo que será determinante en el tipo de sismos a lo largo de la zona de subducción (Kopp, 2013) y por ende el escenario tsunamigénico local para el Pacífico colombiano. 

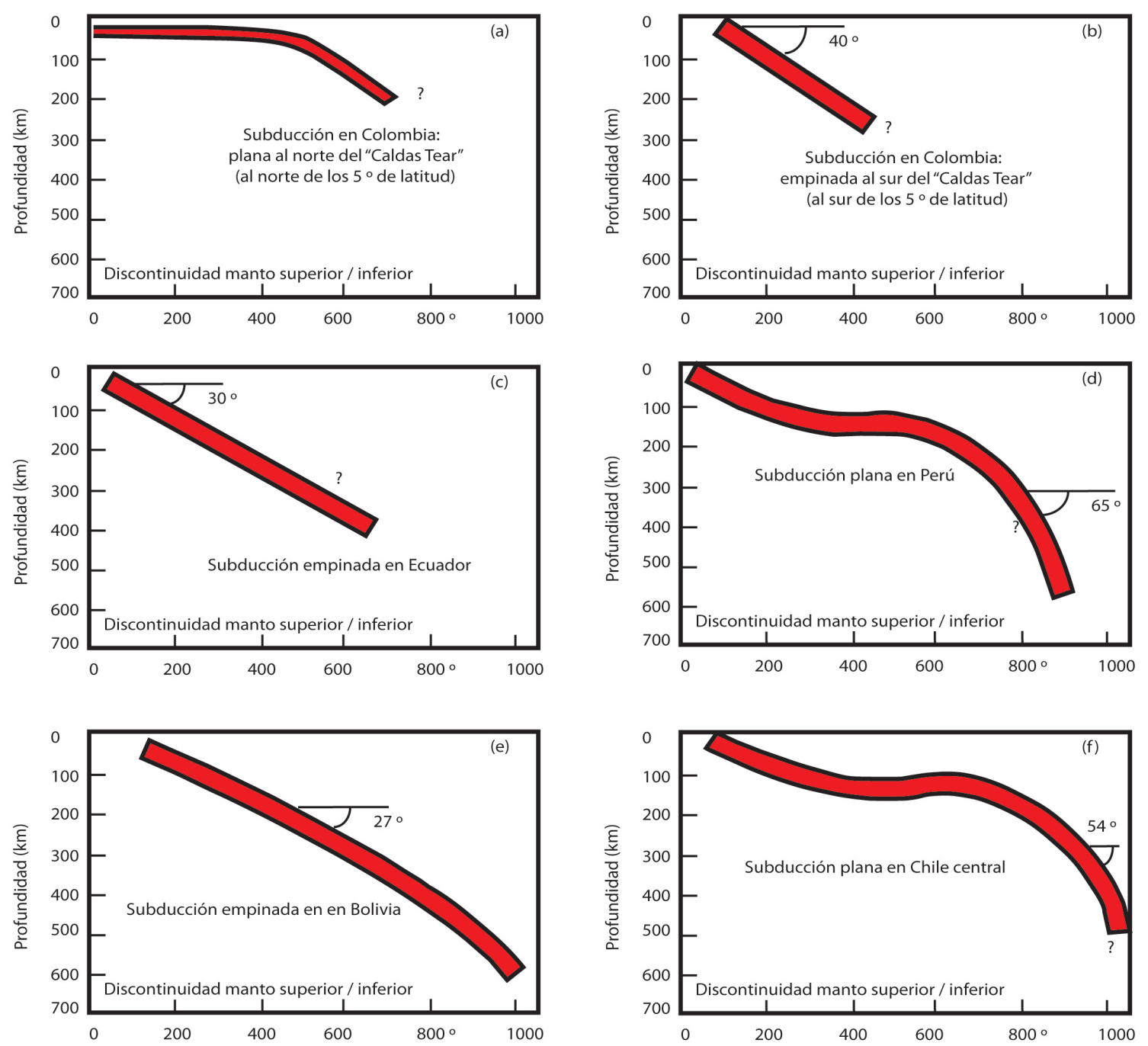

FIGURA 3. Cambios morfo - estructurales de la subducción a lo largo de los Andes. (a) Subducción plana (“flat slab”) al norte de la falla transformante de Coiba (CTF) o "Caldas Tear". (b) Subducción empinada al sur de la CTF, aproximadamente 40 de pendiente (Modificado de Chiarabba et al., 2015). (c) Subducción empinada en la parte central de Ecuador, aproximadamente $30^{\circ}$ de pendiente. (d) Subducción plana en la parte media de Perú. (e) Subducción empinada en Bolivia, aproximadamente $27^{\circ}$ de pendiente. (f) Subducción plana en Chile central (Modificado de Sun et al., 2015).

\section{Geología Generalizada de la Costa Pacífica Colombiana}

La Costa Pacífica Colombiana ha sido dividida en tres grandes zonas conforme a su evolución geológica (FIGURAS 1 y 4): la serranía del Baudó al norte, la sub-cuenca del río San Juan en la parte central y la cuenca Tumaco al sur (Barrero et al., 2007; Borrero et al., 2012).
Tectónicamente la serranía del Baudó hace parte del bloque Chocó y al igual que la mayoría de rocas en la zona (volcánicas máficas principalmente), fue acrecionada contra el continente (Lonsdale and Klitgord, 1978; Keigwin, 1978; Wadge and Burke, 1983; Keller et al., 1989; Duque-Caro, 1990; Kellogg and Vega, 1995; Cediel et al., 2010). Producto de la colisión constante y activa del bloque Chocó, a una velocidad promedio de $2,5 \mathrm{~cm} /$ año (Trenkamp et al., 2002) se observan rasgos 
estructurales activos en el Holoceno como la falla de Bahía Solano, con una velocidad de deslizamiento aproximada de 0,2 a 1 mm/año (González et al., 2014).

En la sub-cuenca del río San Juan se encuentran rocas sedimentarias con edades del Paleoceno al Plioceno divididas en cinco unidades lito-estratigráficas (Cediel et al., 2010) (TABLA 3), suprayacidas por el delta del río San Juan, de edad Holocena (Restrepo and Kjerfve, 2002). El espacio de acomodación en este último está principalmente ligado a subsidencia por compactación y subsidencia co-sísmica (González and Correa, 2001). Tanto en la zona continental como en la zona costera se han reportado fallas con orientaciones preferenciales norte-noreste y este-oeste y componente de movimiento vertical importante que controlan bloques levantados y hundidos, los primeros siendo evidenciados por acantilados en las costas, sin embargo, debido a la gran presencia de depósitos recientes no ha sido posible una caracterización clara en superficie (Cediel et al., 2010).

En la cuenca de Tumaco, sobre el basamento, reposan rocas sedimentarias separadas en seis unidades litoestratigráficas, con una sucesión de Oligoceno a Holoceno (Borrero et al., 2012) (TABLA 4). La cuenca Tumaco guarda continuidad geográfica y similitud geológica con la cuenca Borbón en Ecuador. Estructuralmente, en secciones sísmicas se observan fallas de alto ángulo orientadas preferencialmente en sentido norte-sur, con fallas conjugadas en sentido este-oeste que afectan la sucesión hasta el Plioceno. Tectónicamente producen horsts y grabens; algunos pilares se exponen en superficie como fuertes positivos topográficos (Cediel et al., 2010).

TABLA 3. Estratigrafía de la sub-cuenca del río San Juan (Cediel et al., 2010). Al norte, la Costa Pacífica Colombiana está dominada por rocas volcánicas de carácter máfico, con fuertes expresiones morfológicas evidenciadas en acantilados.

\begin{tabular}{|c|c|c|c|c|c|c|}
\hline$\underset{\mathbb{I}}{\mathbb{5}}$ & $\mid$ & 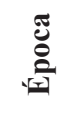 & 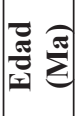 & & Formaciones & Litología \\
\hline \multirow{10}{*}{$\begin{array}{l}8 \\
\frac{3}{0} \\
\text { U. } \\
\stackrel{0}{0}\end{array}$} & \multirow{2}{*}{ 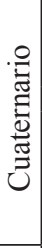 } & $\stackrel{1}{\circ} \stackrel{8}{0}$ & 0,01 & \multirow[t]{2}{*}{$\begin{array}{l}\text { Qal - Qat } \\
\text { Qaf - Qtf } \\
\text { Qb-Qsb }\end{array}$} & Depósitos Recientes & $\begin{array}{l}\text { Depósitos asociados a ríos, abanicos de marea, playas y barras } \\
\text { de arena. }\end{array}$ \\
\hline & & $\begin{array}{l}\frac{0}{0} \\
0 \\
\frac{0}{0.0} \\
\frac{0}{2} \\
\end{array}$ & 1,8 & & & \\
\hline & \multirow{5}{*}{ 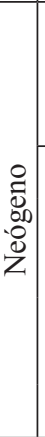 } & 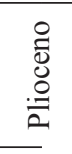 & 8,3 & My & $\begin{array}{l}\text { Formación Marroquín y } \\
\text { Formación Raposo }\end{array}$ & $\begin{array}{c}\text { My: Conglomerados en la base e intercalaciones de areniscas y } \\
\text { lodolitas. } \\
\text { Rp: Conglomerados, areniscas y lodolitas en lentes con } \\
\text { fragmentos de plantas. }\end{array}$ \\
\hline & & \multirow{4}{*}{ 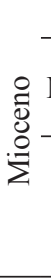 } & 11,6 & & & \\
\hline & & & 15,9 & Co & Formación Condoto & $\begin{array}{l}\text { Miembro superior: Areniscas y conglomerados. } \\
\text { Miembro inferior: Arcillolitas ricas en materia orgánica. }\end{array}$ \\
\hline & & & \multirow[t]{2}{*}{23} & $\mathrm{Mj}$ & \begin{tabular}{|c|} 
Formación Conglomerados \\
de La Mojarra
\end{tabular} & $\begin{array}{l}\text { Espesos conglomerados con intercalaciones de areniscas y } \\
\text { limolitas. Fragmentos de plantas al tope. }\end{array}$ \\
\hline & & & & Is & Formación Istmina & Limolitas, arcillolitas, areniscas y conglomerados. \\
\hline & \multirow{3}{*}{ 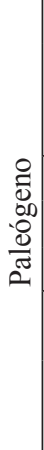 } & 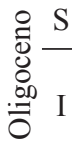 & 33,9 & & & \\
\hline & & 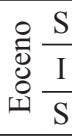 & \begin{tabular}{|l|}
40,4 \\
55,8 \\
\end{tabular} & \multirow[b]{2}{*}{ Ir } & \multirow[b]{2}{*}{ Formación Iró } & \multirow{2}{*}{$\begin{array}{l}\text { Calizas fosilíferas, arcillolitas fósiles y chert. } \\
\text { Edad: Paleoceno - Eoceno? }\end{array}$} \\
\hline & & 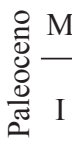 & 61,7 & & & \\
\hline & $\begin{array}{c}\mathrm{Ba} \\
\mathrm{C}\end{array}$ & $\begin{array}{l}\text { amen } \\
\text { etácic }\end{array}$ & & & & \\
\hline
\end{tabular}


TABLA 4. Estratigrafía generalizada de la sub-cuenca de Tumaco (Borrero et al., 2012). En la parte central y sur de la Costa Pacífica Colombiana las rocas son predominantemente sedimentarias de ambientes transicionales y depósitos recientes de carácter deltáico, en ambos casos se generan morfologías suaves.

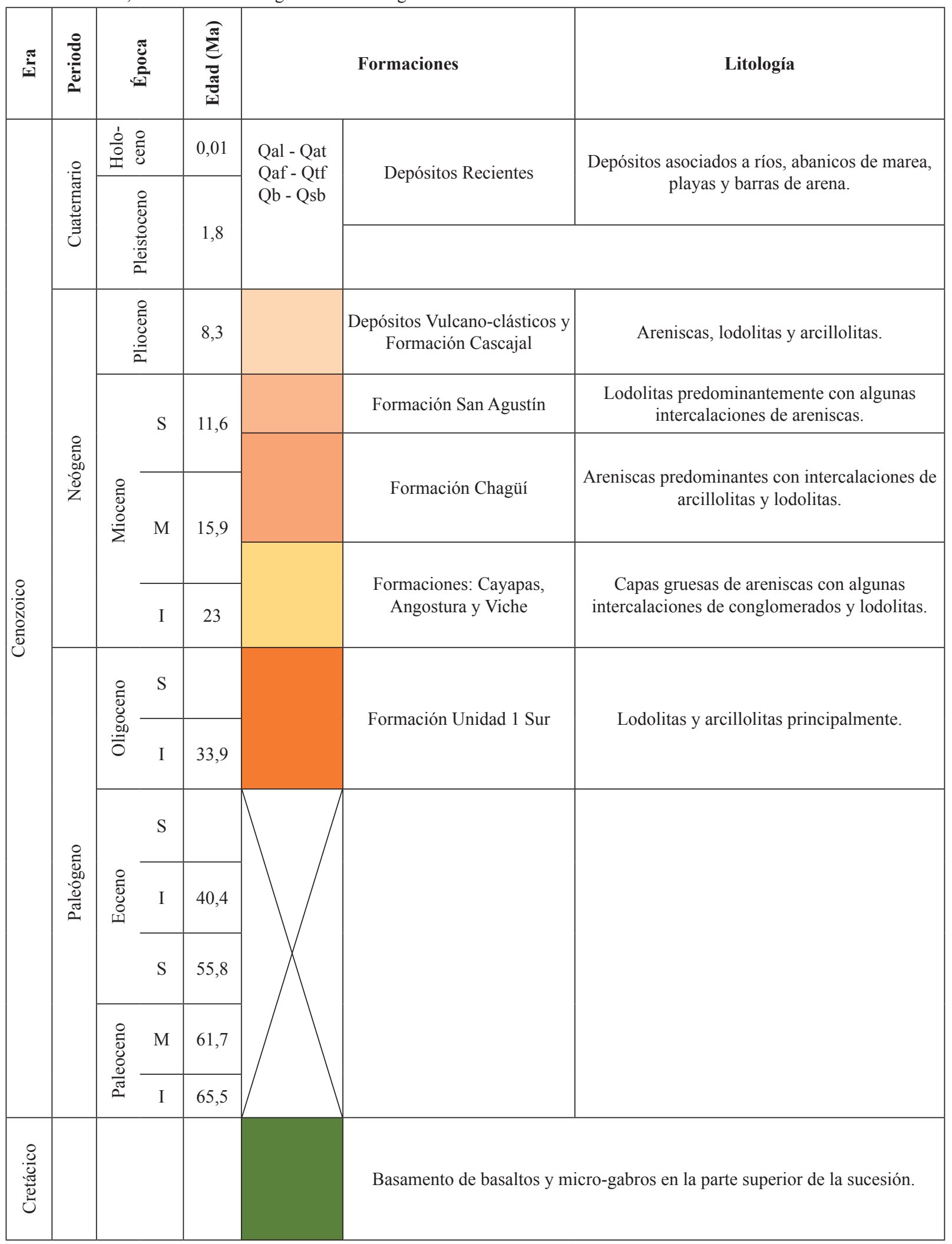


(a)

(b)

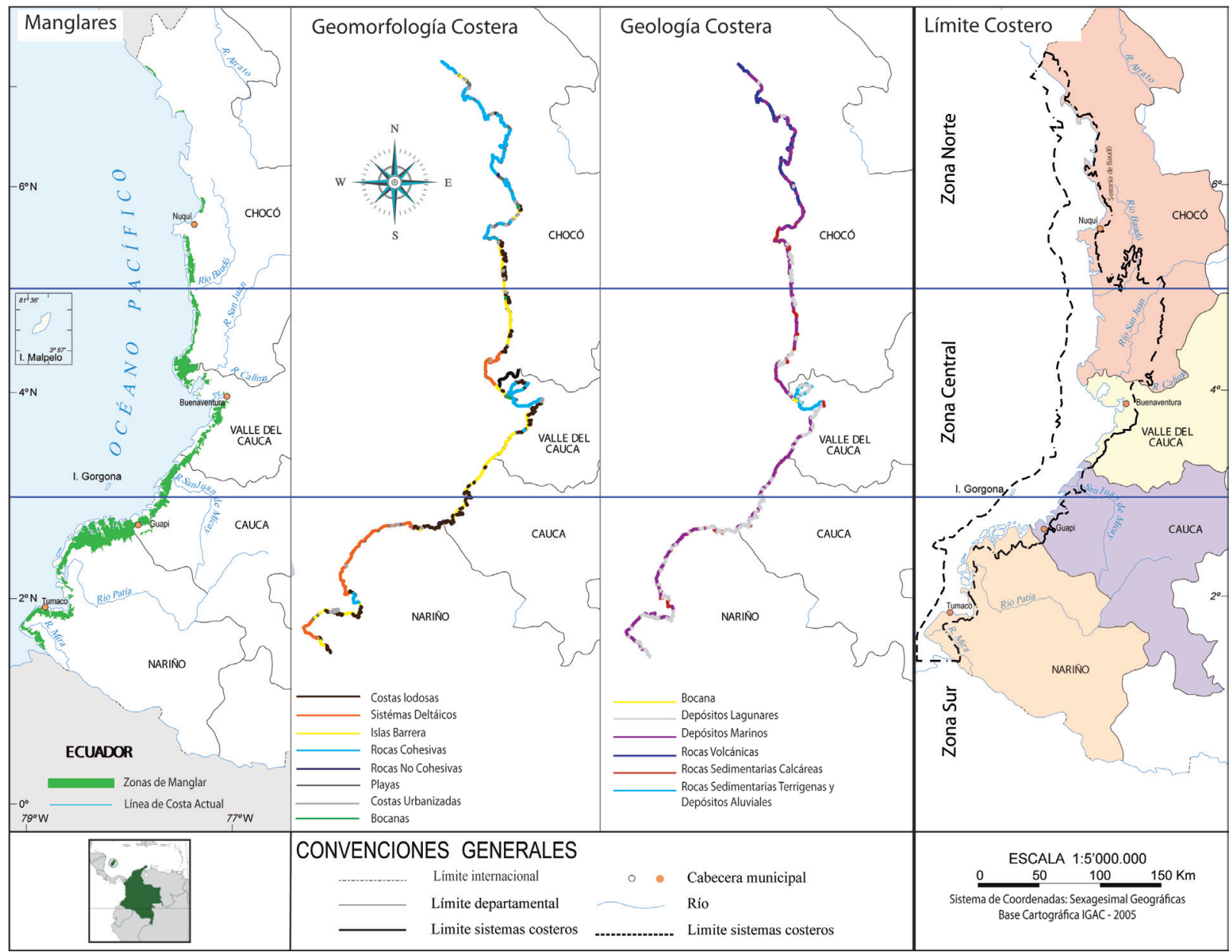

FIGURA 4. (a) Mapa de distribución de manglares, geomorfología y geología en el Pacífico Colombiano. Detallar la relación entre morfología, presencia de manglar y tipo de sedimentos acumulados. En lugares de morfología baja, el desarrollo del manglar es superior. Hacia el norte de la costa pacífica se observan costas acantiladas originadas por levantamiento de bloques y erosión de rocas muy competentes, la costa restante, en su mayoría, presenta morfologías suaves y bajas (compilado y modificado de Posada et al., 2009; base cartográfica IGAC, 2005). (b) División político-administrativa y límite del sistema costero en la Costa Pacífica Colombiana. Es apreciable como hacia el norte de la costa el límite se acerca a la línea costera, mostrando la presencia de acantilados en el serranía del Baudó; en la parte media de la costa el sistema costero es amplio debido a la presencia de la cuenca y delta del río San Juan; hacia el sur su amplitud promedio está ligada a la morfología costera de bajos topográficos (modificado de Posada et al., 2009; base cartográfica IGAC, 2005).

\section{Geomorfología de la Costa Pacífica Colombiana}

La morfología costera en el Pacífico colombiano está principalmente ligada a la tectónica y a los procesos morfo-dinámicos vigentes, de tal manera que las geoformas corresponden a acantilados y plataformas de abrasión en donde la tectónica domina y a coluviones, llanuras aluviales, deltas, playas, islas barrera, planicies mareales y bocanas donde los procesos superficiales tanto terrestres como costeros prevalecen (Posada et al., 2009). En la TABLA 5 se observa una compilación de la distribución porcentual y características de las geoformas a lo largo de esta costa.

El dominio tectónico en la morfología de esta costa es considerable pues gran parte de ésta (26\%), correspondiente a acantilados, está influenciada por levantamientos tectónicos, mostrando que las fallas que controlan los bloques levantados tienen una injerencia importante; esta morfología se observa principalmente hacia la serranía del Baudó (FIGURAS 1 y 4). Desde el punto de vista tsunamigénico, dichos bloques son 
significativos debido a que la inundación en estas zonas puede ser menor, ya que estos acantilados presentan alturas de hasta $50 \mathrm{~m}$ (Posada et al., 2009). No obstante, la ocurrencia de sedimentos tsunamigénicos supra-yacentes en los acantilados mostraría cotas altas de inundaciones pasadas. Como aún ningún estudio se ha hecho sobre la afinidad entre la litología de las unidades o formaciones aflorantes en los acantilados de edades pre-Cuaternarias y posibles eventos paleotsunamigénicos $\mathrm{y} / \mathrm{o}$ efectos o deformaciones cosísmicas, no se puede precisar con certeza aún si fenómenos catastróficos de este tipo existieron en pasados tiempo geológicos aflorantes a lo largo de la Costa Pacífica Colombiana.

TABLA 5. Geomorfología generalizada de la Costa Pacífica Colombiana. Se destaca el tipo de costa, morfología, dominio geológico y extensión. Con base en Martínez et al. (2005) y Posada et al. (2009).

\begin{tabular}{|c|c|c|c|}
\hline Tipo de Costa & Morfología & Dominio Geológico/Litología & $\begin{array}{l}\text { Extensión }(\mathrm{km}) / \\
\text { Porcentaje de } \\
\text { Litoral Pacífico }\end{array}$ \\
\hline $\begin{array}{l}\text { Costa con rocas } \\
\text { cohesivas }\end{array}$ & $\begin{array}{l}\text { Acantilados fuertes y plataformas } \\
\text { de erosión levantadas. }\end{array}$ & $\begin{array}{l}\text { Tectónico/Rocas fuertemente consolidadas } \\
\text { (resistentes a meteorización y erosión). }\end{array}$ & $445 / 25 \%$ \\
\hline $\begin{array}{l}\text { Costa con rocas no } \\
\text { cohesivas }\end{array}$ & $\begin{array}{c}\text { Acantilados suaves con entrantes y } \\
\text { salientes marinas. }\end{array}$ & $\begin{array}{l}\text { Tectónico/Rocas poco consolidadas y/o } \\
\text { fracturadas (frágiles a la meteorización y } \\
\text { erosión). }\end{array}$ & $15 / 1 \%$ \\
\hline $\begin{array}{l}\text { Playas (sin incluir islas } \\
\text { barrera } y \text { deltas) }\end{array}$ & $\begin{array}{c}\text { Playas cóncavas, bajos y deltas de } \\
\text { marea. }\end{array}$ & $\begin{array}{l}\text { Morfo-dinámico depositacional - erosional } \\
\text { por oleaje/Arenas y lodos. }\end{array}$ & $122 / 7 \%$ \\
\hline Islas barrera & $\begin{array}{l}\text { Cuerpos elongados paralelos a } \\
\text { la costa separados por esteros } \\
\text { (contiene playas y cordones } \\
\text { litorales). }\end{array}$ & $\begin{array}{c}\text { Deriva litoral (morfo-dinámico } \\
\text { depositacional)/Arenas de frente de playa. }\end{array}$ & $316 / 18 \%$ \\
\hline $\begin{array}{l}\text { Plano inter-mareal } \\
\text { vegetado }\end{array}$ & $\begin{array}{l}\text { Pantanos vegetados por manglar } \\
\text { con morfologías planas a semi- } \\
\text { cóncavas. }\end{array}$ & $\begin{array}{c}\text { Morfo-dinámico depositacional/Lodos } \\
\text { transportados con alto contenido orgánico } \\
\text { in-situ. }\end{array}$ & $419 / 24 \%$ \\
\hline Sistemas deltaicos & $\begin{array}{c}\text { Planos y lóbulos; algunas islas } \\
\text { barrera, lagunas estuarinas y } \\
\text { pantanos de manglar superpuestos. }\end{array}$ & $\begin{array}{c}\text { Morfo-dinámico depositacional y tectónico } \\
\text { (secundario)/Arenas y lodos continentales } \\
\text { y marinos. }\end{array}$ & $272 / 15 \%$ \\
\hline Estuarios & Lagunas estuarinas amplias. & $\begin{array}{l}\text { Mareal y Aluvial/Lodos y arenas } \\
\text { continentales principalmente. }\end{array}$ & $116 / 7 \%$ \\
\hline Costas urbanizadas & $\begin{array}{l}\text { Poblaciones construidas } \\
\text { principalmente en playas e islas } \\
\text { barrera rodeadas por manglares y } \\
\text { bajos lodosos. }\end{array}$ & $\begin{array}{c}\text { Morfo-dinámico erosional y } \\
\text { depositacional/Arenas y lodos de frente de } \\
\text { playa. }\end{array}$ & $58 / 3 \%$ \\
\hline & & Total en la Costa Pacífica Colombiana & $1.763 \mathrm{~km} / 100 \%$ \\
\hline
\end{tabular}

Por el contrario, morfológicamente, al menos un $74 \%$ de esta costa son planicies o bajos topográficos, más susceptibles a inundaciones por sobre-lavado, tormentas severas, marejadas y/o tsunamis (FIGURA 4). Es aquí donde la probabilidad de encontrar evidencias por inundaciones anteriores es superior, por lo que son áreas de mayor interés para la realización no solo de investigaciones de evidencia física de paleo-tsunamis, sino también de la elaboración de mapas de amenaza por tsunami ya que son áreas en las que ha existido mayor concentración de comunidades costeras tanto en tiempos pasados como en la actualidad (FIGURA 4). En la FIGURA 5, se puede observar la distribución morfológica de la costa del departamento de Nariño, en la cual se evidencia que al menos $90 \%$ de esta son zonas bajas altamente susceptibles a inundaciones marinas, incluyendo tsunamis.

Hídricamente, la Costa Pacífica Colombiana se encuentra irrigada por numerosos ríos que descargan toda la escorrentía de la cordillera Occidental y la serranía del Baudó en el océano Pacífico; dentro de los más grandes 
están los ríos Mira, Patía, San Juan de Micay, San Juan y Baudó (FIGURA 4). Morfológicamente son ríos de tramos relativamente cortos y de grandes caudales (e.g. río San Juan) con descargas entre $600 \mathrm{~m}^{3} / \mathrm{s}$ a $6,000 \mathrm{~m}^{3} / \mathrm{s}$, considerado el río de mayor caudal de Sur América (Restrepo and Kjerfve, 2002), los cuales desarrollan importantes estuarios y deltas en sus frentes costeros (Posada et al., 2009).

Durante un evento de tsunami los estuarios se comportan como embudos que por efectos hidrodinámicos concentran la energía a medida que la onda se acerca al ápice, conllevando a un incremento aún más dramático de la altura de la masa de agua, generando así un impacto mayor en esta extremidad interior del estuario. Colateralmente, las aguas de inundación por tsunami penetran continente adentro por cauces de ríos, siendo estos canales ideales de propagación de la inundación en zonas relativamente alejadas de la costa, aumentando así la distancia y área de impacto tierra adentro. Efectos de este tipo han sido estudiados en sitios como Port Alberni en la Isla de Vancouver, Costa Pacífica de Canadá (e.g. Clague et al., 1994; Clague and Bobrowsky, 1999; Clague et al., 2000), en cuyo ápice se concentró gran parte de la energía acarreada por el tsunami de Alaska de 1964 que se propagó a lo largo de toda la costa Pacífica de ambos continentes americanos, dejando importantes niveles de arenas tsunamigénicas en los pantanos inter-mareales existentes en ésta zona de la isla (FIGURA 2).

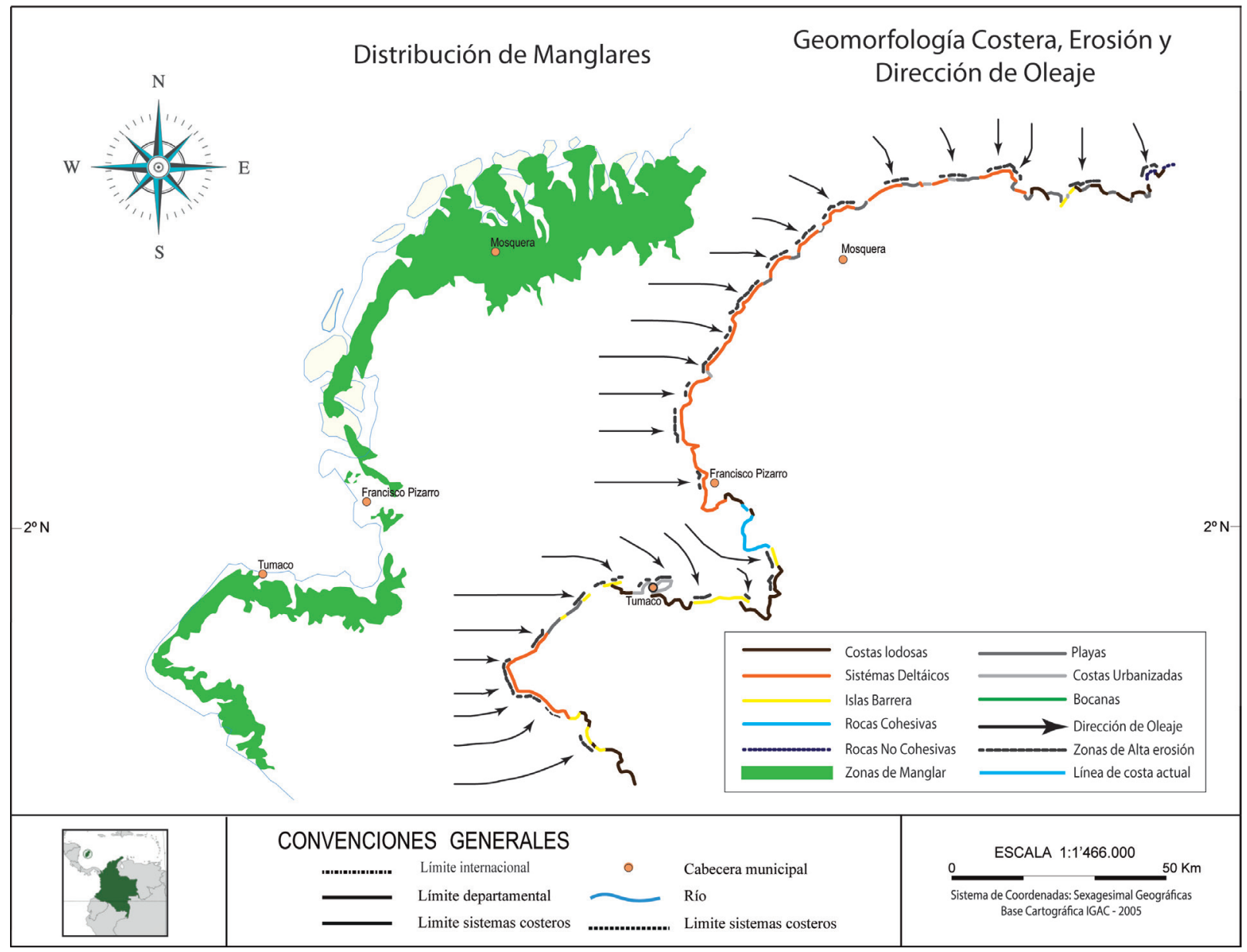

FIGURA 5. Distribución de la erosión costera, dirección de oleaje y geomorfología en la costa pacífica nariñense. Se pueden apreciar la dirección promedio del tren de oleaje actuando sobre la costa y generando erosión. La localización de la erosión costera permite suponer lugares de menor probabilidad de conservación y disponibilidad de sedimentos. El manglar en la costa pacífica nariñense puede comportarse como barrera natural frente a eventos por tsunami (compilado y modificado de Posada et al., 2009; base cartográfica IGAC, 2005). 


\section{Subsidencia y levantamiento reciente en la Costa Pacífica Colombiana}

Conocer las tasas de subsidencia o levantamiento de las zonas costeras permite saber las tazas de sedimentación a lo largo de la costa, la factibilidad de su conservación, el espacio tridimensional que tiene para nueva acumulación o cuáles son las zonas de mayor afectación por inundación por tsunami, así como las zonas de posible erosión y/o depositación por este fenómeno.

En la serranía del Baudó se observan acantilados superiores a los $200 \mathrm{~m}$ de altura, confirmando el levantamiento progresivo de la cadena montañosa. Trabajos recientes proponen un levantamiento rápido y pulsátil, incluyendo levantamientos decimétricos de carácter co-sísmico. Las velocidades aproximadas de levantamiento progresivo son del orden de $0,7 \mathrm{~mm} /$ año en el norte y de $1 \mathrm{~mm} / \mathrm{año}$ al sur (González et al., 2014). Martínez and López (2011) proponen una tasa de subsidencia para la zona de la llanura deltaica del río San Juan de 9,5 mm/año en los últimos 10.000 años, generada posiblemente por compactación.

En Ecuador se han registrado levantamientos de bloques, de carácter co-sísmico, como ha sido reportado por Dumont et al. (2006) en la Costa Pacífica Ecuatoriana, en donde el delta de Cayapas-Santiago modificó su drenaje luego de un sismo en la zona de EsmeraldasTumaco hace 2.800 a 3.200 años atrás.

Aunque existen estudios que hablan de las velocidades de subsidencia del Oligoceno al Holoceno en la Cuenca Tumaco (e.g. Borrero et al., 2012) y en el Holoceno en el delta del río San Juan (e.g. Martínez and López, 2011), no se han realizado a profundidad estudios que revelen las velocidades precisas de subsidencia durante el Holoceno para localidades de interés específico, como áreas urbanizadas o de interés económico (e.g. Tumaco, Buenaventura, Guapi, Bajo Baudó, Nuquí o Bahía Solano).

\section{Subsidencia Co-Sísmica}

Además de la subsidencia co-sísmica propuesta por González and Correa (2001) en el delta del río San Juan, se han hecho tres estudios que reportan fenómenos cosísmicos en la Costa Pacífica Colombiana; el primero, asociado al sismo del 26 de septiembre de 1970, de magnitud Mw 6,5 (Escala de Magnitud de Momento), que produjo un espacio de acomodación entre 20 y 30 cm en Bahía Solano (Restrepo, 1971; González et al., 2014); el segundo, reporta la presencia de tres niveles de turba enterrada en 800 años (entre 1181 y 1981), también para Bahía Solano (Page and James, 1981); y el tercero, asociado al sismo de Tumaco de 1979, Mw 7,9, que causó una subsidencia promedio de 1,6 $\mathrm{m}$ a lo largo de $200 \mathrm{~km}$ de costa (Herd et al., 1981).

La evidencia de subsidencia súbita co-sísmica propuesta a lo largo de la Costa Pacífica Colombiana, permite suponer que la conservación de sedimentos asociados a paleotsunamis es bastante buena, no obstante, dicha conservación no solo depende del fenómeno sísmico, sino que también depende de la intensidad erosiva del mar por oleaje, mareas y sobre-lavado, fenómenos activos en la zona litoral, además de otros fenómenos post-depositacionales como retrabajamiento por procesos geológicos o biológicos (e.g. licuefacción, intrusiones, madrigueras, raíces, etc.), hasta antropogénicos (e.g. excavaciones, construcciones, reutilización de la tierra, etc.).

\section{Generalidades sobre Tsunamis en el Pacífico Colombiano}

En los últimos años la investigación en torno a fenómenos de tsunami en el Pacífico Colombiano ha venido aumentando poco a poco, con esfuerzos focalizados principalmente en el modelamiento numérico de posibles frentes de tsunami (e.g. Caballero y Ortíz, 2003; Cardona, 2004, 2005; Esquivel, 2006; Restrepo y Otero, 2007; Sánchez et al., 2013; DIMARCCCP, 2013), mapas de inundación (e.g. Bastidas y Puentes, 2008; González y Sánchez, 2011; Sánchez, 2012; Sánchez et al., 2013; DIMAR-CCCP, 2013), recuentos históricos (e.g. Ramírez y Goberna, 1980; OSSO, 1992; Otero et al., 2013; DIMAR-CCCP, 2013), y estimación de la vulnerabilidad (e.g. Peralta et al., 2003; DIMAR-CCCP, 2013), para las localidades de Buenaventura y Tumaco fundamentalmente (FIGURA 6). Lo anterior muestra un esfuerzo valioso y necesario, pero que requiere ser alimentado con datos que muestren el comportamiento del fenómeno en sí, su recurrencia, magnitud, intensidad, extensión y alcance, al igual que su origen. Estos datos se obtienen con investigaciones detalladas de la evidencia física generada por el tsunami, la cual debe estar preservada ya sea en forma de depósitos sedimentarios (e.g. láminas u horizontes, ver FIGURA 2) en el subsuelo de la zona afectada, o en forma de expresiones geomorfológicas (e.g. rasgos erosivos), para así poder determinar la extensión real de afectación por estos eventos, tanto antiguos como históricos. $\mathrm{La}$ combinación de toda esta información, más mapas de aceleración sísmica y de suelos de las áreas específicas, de geomorfología costera, de geología y batimetría de la plataforma, estuarios y lagunas costeras, permitirá la correcta elaboración de mapas de amenaza por tsunami. Cada herramienta por sí sola no es suficiente argumento, siendo necesario integrarlos en conjunto. 


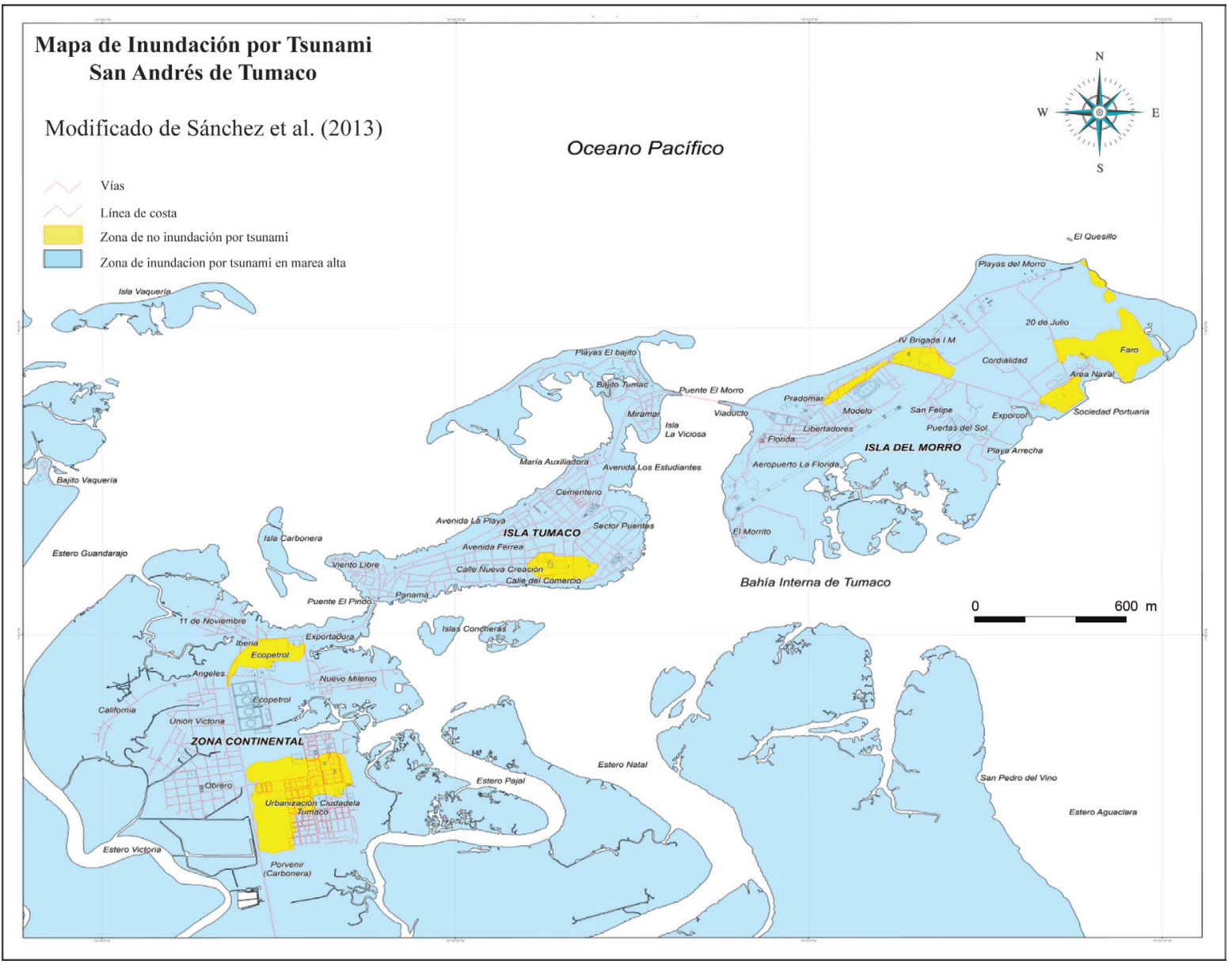

FIGURA 6. Mapa de inundación de San Andrés de Tumaco. Propuesta de Sánchez et al. (2013). Desarrollado por la Dirección General Marítima (DIMAR) y el Centro de Investigaciones Hidrográficas y Oceanográficas del Pacífico (CIOH, antes CCCP). Mapa generado a partir de modelamiento numérico de inundación por tsunamis.

Sedimentológicamente, la plataforma somera y continental de la Costa Pacífica Colombiana está constituida en un $95 \%$ por líticos de tamaño de grano entre arena y lodo, y un 5\% de bio-clástos de tamaños igualmente variables entre arenas y lodos. En ambos casos no hay una tendencia regular específica a lo largo de esta costa (CIOH, 2005; Molina y Mirmand, 1992). El conocimiento de los sedimentos de la plataforma, al igual que el conocimiento de la litología de la margen costera, permite dimensionar y prever el tipo de sedimentos transportados, erosionados, acarreados y depositados por un tsunami, y así ser de ayuda en la caracterización e identificación de unidades anómalas encontradas en el sub-suelo cuando se elaboren estudios de búsqueda de evidencia física, sedimentológica, dejada por paleo-tsunamis. Hasta el momento no se han desarrollado estudios enfocados a la identificación, caracterización y/o datación de paleo-tsunamis en las costas colombianas, aún sabiendo de la ocurrencia de tsunamis históricos (TABLA1) en tiempos relativamente recientes, sin descartar la posibilidad de ocurrencia en tiempos geológicos mucho más antiguos. Es posible que estos se hayan preservado, pues como se ha descrito antes, existen condiciones tecto-sedimentarias que favorecen su conservación. No obstante, es igualmente posible que el registro sea escaso, ya que en la Costa Pacífica Colombiana los eventos de sobre-lavado o marejadas fuertes son muy comunes (e.g. Morton et al., 2000 ), los cuales podrían erosionar registros previos y/o confundirse con depósitos de paleo-tsunamis.

Los eventos de sobre-lavado, comunes en el Pacífico colombiano (FIGURA 7), pueden ser erosivos o depositacionales, pues se producen cuando niveles altos anormales del mar, estuarios y lagunas costeras, sobrepasan la topografía positiva y penetran costa adentro. Su génesis no es necesariamente asociada a tormentas y su efecto es considerable, a tal punto que son capaces de erosionar grandes islas barreras o dejar grandes cuñas sedimentarias (Morton et al., 2000). 


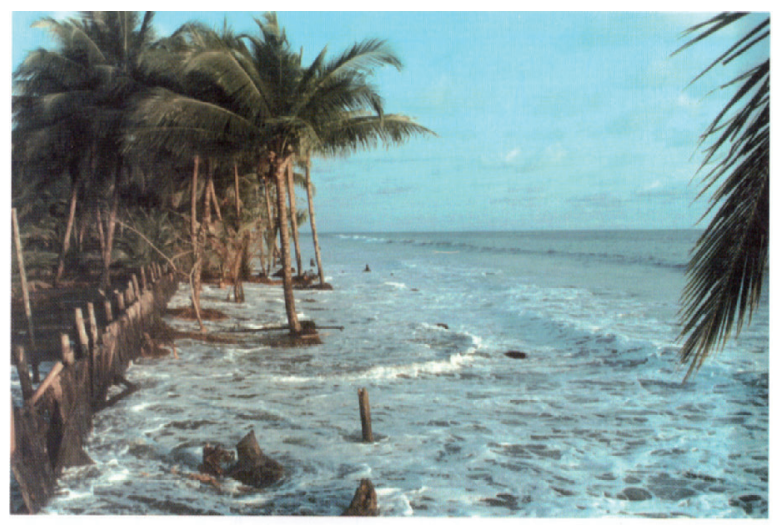

(a)

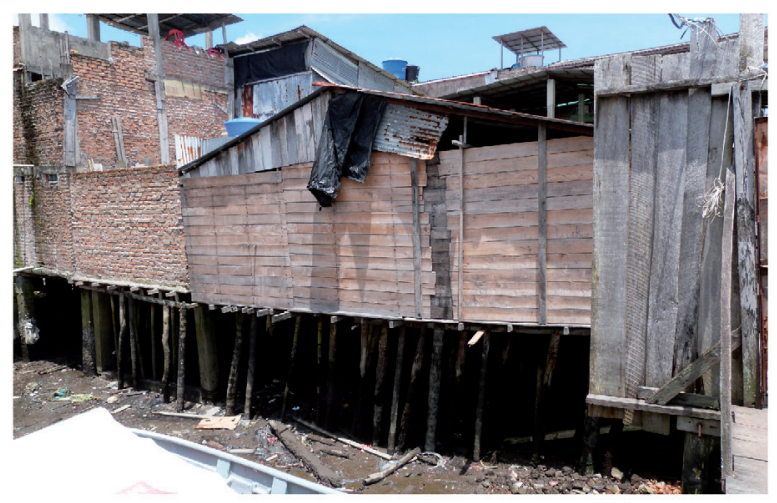

(c)

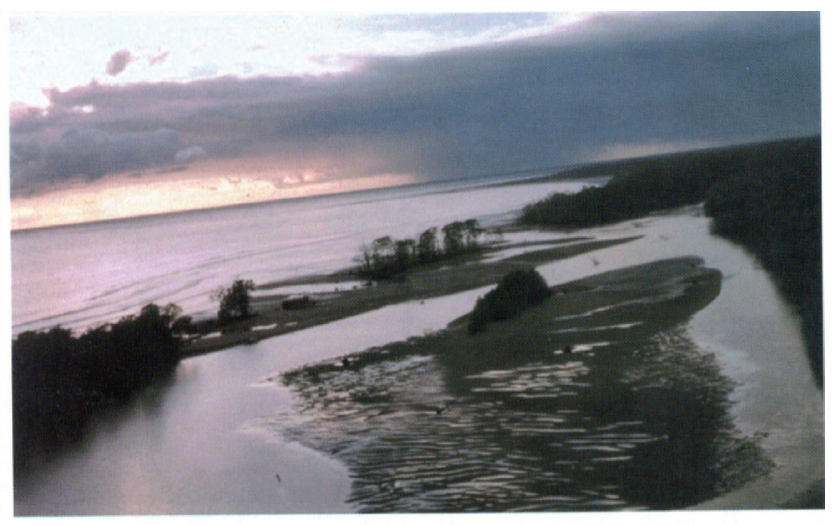

(b)

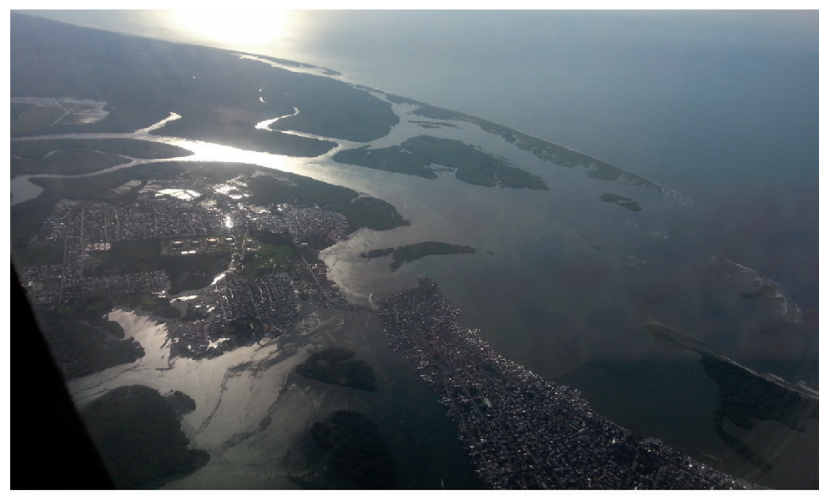

(d)

FIGURA 7. (a) Inicio de fenómenos de sobre-lavado en las playas de El Choncho, delta del río San Juan, Costa Pacífica Colombiana (1997). (b) Isla del Choncho cuatro meses después del sobre-lavado constante (julio 1998) (c.f. Morton et al. 2002). (c) Fotografía de las construcciones palafíticas en San Andrés de Tumaco, zona del muelle de la Cruz Roja Colombiana, barrio La Taguera, sector bahía interna de Tumaco frente a Estero Natal. Construcciones livianas y poco resistentes frente a fenómenos mecánicos como inundaciones por tsunamis (marzo 2015). (d) Vista aérea parcial del municipio de Tumaco, sectores El Pindo - La Ciudadela (zona continental) y extremo oeste de la isla de Tumaco. Ver la diversidad de zonas topográficamente bajas de la bahía de Tumaco y la sobrepoblación de las islas (marzo 2015).

\section{MARCO BIOLÓGICO}

En la Costa Pacífica Colombiana el clima está influenciado por la concurrencia de corrientes atmosféricas que forman la Zona de Convergencia Intertropical. En general se tienen temperaturas promedio entre $26^{\circ}$ y $28^{\circ}$ $\mathrm{C}$ y lluvias con promedios anuales entre $3.000 \mathrm{~mm}$ y 10.000 mm (Posada et al., 2009; González et al., 2014). Bajo el dominio climático, la vegetación pacífica consiste en varios sub-tipos de bosque húmedo tropical (Sánchez, 2012). En la zona costera que va desde Nariño hasta la parte media del Chocó se desarrollan en su mayoría pantanos de manglar y de transición, con especies variadas de mangle, palmas, helechos y rastrojos (FIGURAS 4 y 5) (IGAC e INGEOMINAS, 2008); el 30\% restante de la costa pacífica depende de la morfología acantilada de la serranía del Baudó, en donde se desarrolla una vegetación de selva húmeda espesa (Posada et al., 2009).
La presencia de vegetación de manglar en zonas costeras bajas contribuye al amortiguamiento del impacto generado por la ola de tsunami en su llegada a la costa, el ejemplo más claro es el tsunami de Indonesia del 2004, en donde se observo que las zonas con manglar fueron significativamente menos impactadas que las descubiertas (Kathiresan and Rajendran, 2005; Alongi, 2008; Barbier, 2008).

Aunque se conoce la vegetación presente en la costa pacífica y se han desarrollado estudios que muestran los cambios progresivos de la vegetación en el Holoceno (e.g. Urrego y Ramírez, 1999; González, 2003) y su modificación antropogénica (OSSO, 1992), no existen investigaciones publicadas sobre cambios abruptos de la vegetación asociados a fenómenos marinos intensos y/o cambios bruscos co-sísmicos. 
El conocimiento de los cambios repentinos e intensos de origen marino y/o co-sísmico, como por ejemplo los eventos de sobre-lavado (i.e. Morton et al., 2000) y subsidencia repentina debido a algún evento tectónico, es una herramienta importante en la investigación de paleotsunamis; ejemplos claros son los estudios realizados en las costas de Costa Rica, Ecuador y México, en donde se han registrado cambios en la vegetación como efecto de la subducción de dorsales (de Gracia et al., 2012), y la inundación por tsunamis (Ramírez-Herrera, 2011; Lim et al., 2013).

\section{ANTROPOLOGÍA, ARQUEOLOGÍA E HISTORIA}

Aunque los tsunamis han sucedido a lo largo del tiempo geológico es importante considerar su interacción con el ser humano. La tradición oral (y en algunas regiones, la escrita) de culturas ancestrales pone en evidencia la ocurrencia de eventos de tsunami, atribuyéndolos a grandes y terribles castigos del mar, dioses o la Madre Tierra. Las investigaciones científicas sobre tsunamis solo empezaron en el siglo XX y el fidedigno registro instrumental de datos sísmicos solo a partir de 1950 (Soloviev and Go, 1974; NGDC, 2000), por ello, es importante constatar la ocurrencia de estos fenómenos en registros aún más antiguos, ya sean estos tradiciones orales, simbolismos o historias escritas por antiguas comunidades y civilizaciones (e.g. Hutchinson and McMillan, 1997; Goff and McFaden, 2001).

Un ejemplo de la importancia de involucrar la antropología, arqueología e historia en las investigaciones de paleo-tsunamis, es el gran tsunami del 26 de enero de 1700 (Satake et al., 1996; Atwater et al., 2005), producido por el más reciente megasismo inter-placas $\left(\mathrm{M}_{\mathrm{w}} 9,0\right)$ de la zona de subducción de Cascadia (costa Pacífica de Canadá - EE.UU). Este tsunami fue registrado únicamente en textos antiguos japoneses, ya que el registro escrito en esta región del "Nuevo Mundo" solo empezó después de la llegada del Capitán James Cook a estas costas en 1778 (Moziño, 1792). Obviamente, la constatación de la evidencia geológica y el hallazgo de depósitos de tsunami a lo largo de las costas del Pacífico de Norte América, validó el suceso descrito en Japón y la edad precisa del evento fue corroborada gracias a dichos escritos.

A pesar de las (a veces) fabulosas, fantasiosas o míticas connotaciones de las tradiciones orales indígenas, la ocurrencia de sismos y tsunamis ha sido reportada por pueblos aborígenes desde tiempos atrás, y en la ausencia de evidencia geológica, es preciso también tener en cuenta estos relatos.

\section{Marco Antropológico}

En el Pacífico colombiano se reconocen tres tipos de poblaciones, afroamericanos, amerindios y blancos, además de las mezclas raciales entre ellos (Maya, 2003). Aunque actualmente el dominio poblacional es de los afroamericanos, desde tiempos ancestrales los indígenas han tenido presencia en la región, a tal punto que hasta 1997 había 218 comunidades, con una proporción mayoritaria del $65 \%$ de la comunidad Emberá (DNP, 1997). Mitológicamente, los Emberá han descrito el fenómeno sísmico bajo varias leyendas (Betania, 1964, detallado en Velasco, 2015). Sin embargo, no se han encontrado aún documentos que hablen de leyendas específicas en torno a tsunamis.

Conocer a profundidad a las comunidades, su comportamiento y tradiciones orales permite a los investigadores de paleo-tsunamis saber si han existido eventos pasados de gran impacto que han dejado un registro histórico en tradiciones orales, leyendas o mitos, que sirvan como nivel de referencia para la búsqueda de la evidencia física. Un ejemplo claro es el estudio realizado por Hutchinson and McMillan (1997), quienes a partir de las tradiciones orales de una cultura indígena del Pacífico canadiense pudieron asociar eventos sísmicos y tsunamigénicos al desplazamiento y desaparición de aldeas enteras en esa región.

Con respecto a la ubicación, amerindios y afroamericanos se han concentrado en pequeños asentamientos a lo largo de la costa pacífica, principalmente en las cabeceras y orillas de ríos y en llanuras costeras; éstas aldeas han crecido y se han agrupado desde la época de la minería colonial hasta formar los actuales municipios de la región (Maya, 2003).

Tanto en las construcciones costeras como fluviales se observan estructuras palafíticas (levantadas en pilotes de $60 \mathrm{~cm}$ a $4 \mathrm{~m}$ de altura), conectadas entre sí por "puentes" (tablas) en madera. La presencia de este tipo de construcción se debe a la necesidad de las comunidades de acceso a vivienda económica, de protección contra constantes inundaciones mareales y fluviales, y protección contra la fauna silvestre de la zona. En municipios como Tumaco, Guapi, Buenaventura, Nuquí y Bahía Solano (FIGURA 4), entre otros, existe una combinación de construcciones palafíticas y de concreto, éstas últimas realizadas en las zonas centrales o más elevadas de las islas barrera, o hacia el continente (FIGURA 7) (Maya, 2003). La distribución de las construcciones palafíticas es variable a lo largo de la costa. En Tumaco por ejemplo, las construcciones palafíticas alcanzan un $30 \%$ de la vivienda total, en otros lugares como aldeas aisladas 
la construcción es netamente de este tipo (Steer et al., 2008; Quiñónez, 2011). El estilo de construcción de las viviendas en comunidades costeras va influenciar tanto el grado de vulnerabilidad de dicha población ante la amenaza por tsunami, como el riesgo. No es lo mismo tener construcciones palafíticas que de concreto ante las fuerzas destructivas de un tsunami, no solo por el posible nivel de destrucción de las viviendas, sino que estos objetos u escombros se convierten a su vez en peligrosas armas de impacto.
Las medidas que se deben tomar en cuanto a la evaluación de la amenaza natural en un sitio específico, involucran un enfoque de evaluación no solo de la amenaza física como tal, sino también de la comunidad: (a) Valoración del grado de exposición a la amenaza; (b) Evaluación de la sensibilidad de la comunidad a la amenaza (e.g. preparación de la comunidad, recursos financieros, educación, etc.). Las definiciones de riesgo, amenaza y vulnerabilidad, entre otras, pueden ser consultadas en el glosario (TABLA 6).

TABLA 6. Glosario de terminología general utilizada en gestión del riesgo y prevención de desastres naturales con sus respectivas palabras / traducción al Inglés (en itálicas).

PALABRA

Adaptación

Adaptation

Amenaza

Hazard

Desastre

Disaster

Exposición

Exposure

Mitigación

Mitigation

Probabilidad

Probability

Pronóstico

Forecast

Riesgo

Risk

Sensibilidad

Sensitivity

Vulnerabilidad

Vulnerability

\section{SIGNIFICADO}

El hecho de aceptar que una amenaza pueda ocurrir o que no puede ser mitigada completamente o eliminada

El hecho de tomar acciones que reduzcan no solo el impacto sino también la sensibilidad y vulnerabilidad de la comunidad

Fenómeno natural que causa problemas a la población

Evento que involucra un número significativo de personas y/o de un significante daño económico

(Si un fenómeno natural ocurre en una isla desértica, este no genera un desastre)

El grado al que puede llegar un riesgo o fenómeno natural

Toda persona y/o propiedad que pueda verse afectada por un desastre natural está expuesta a dicha amenaza

El hecho de tomar acciones para físicamente reducir la exposición de una comunidad a una amenaza

Medida estadística de que un evento particular ocurra

Intervalo de Recurrencia (periodicidad)

El número promedio de años de ocurrencia entre eventos del mismo tipo y cierta magnitud en una localidad específica

La probabilidad de que una comunidad y/o propiedad se vea afectada por un evento

La probabilidad de pérdidas (humanas, salud, propiedad, bienes, servicios, etc) que puedan ser ocasionadas por una amenaza

$$
\text { Riesgo }=\text { Amenaza } * \text { Vulnerabilidad }
$$

Grado potencial de afectación a un individuo o comunidad causado por un riesgo natural

Grado de afectación negativa y/o adversa a un individuo, comunidad o sistema causado por un riesgo natural

Condición resultante de factores o procesos físicos, sociales, económicos y ambientales que incrementan la susceptibilidad de una comunidad al impacto de una amenaza

Vulnerabilidad $=$ Exposición + Sensibilidad 


\section{Marco Arqueológico}

Como ha sucedido en otras disciplinas, la investigación arqueológica a lo largo del Pacífico colombiano no ha sido muy profunda, focalizándose únicamente en la parte sur, desde Guapi hasta Tumaco, y en el límite Ecuador-Colombia, y asociado a la distribución de las sociedades Tumaco y La Tolita (e.g. Patiño, 1988, 1992, 1993, 2003a, 2003b) (c.f. Velasco, 2015).

Registros arqueológicos de culturas pre-hispánicas muestran actividad desde al menos el año 1000 B.C. en el norte de Ecuador y evolución a lo largo del tiempo hasta llegar a la denominada sociedad Tumaco - La Tolita, comprendida entre 400 B.C. y A.D. 500. A partir de esta evidencia, también se han podido interpretar actividades de agricultura, pesca, cerámica, orfebrería e intercambio de productos y bienes suntuarios, a través de rutas terrestres y marítimas entre los diferentes centros político económicos de la Costa Pacífica de Colombia y Ecuador (Patiño, 1993, 2003a).

Entre los años A.D. 400 a 500 se observaron cambios dramáticos relacionados con un decaimiento cultural a lo largo de todos los sitios costeros (Patiño, 1992), el cual no ha sido analizado a profundidad y algunos autores le atribuyen causas político - económicas (e.g. Bouchard, 1989). Alrededor del A.D. 600, el marco cultural cambia, observándose que los grupos dejan las zonas costeras y de manglar, y penetran en el continente (Patiño, 1992).

Aunque existen trabajos arqueológicos descriptivos, no se han enlazado las interpretaciones de posibles cambios por fenómenos naturales, como es el caso del trabajo realizado por Hutchinson and McMillan (1997) para la zona de subducción de Cascadia en Canadá.

\section{Marco Histórico}

Hasta el momento, en Colombia se tienen registros históricos de tsunamis cercanos (fuente ligada a la zona de subducción de Nazca bajo la placa Suramericana) ocurridos en 1882, 1904, 1906, 1942, 1958 y 1979 (TABLA 1). Los tsunamis de 1882 y 1904 sólo aparecen reportados en el Centro Nacional para Información Ambiental (NGDC, por sus siglas en inglés) EE.UU, mas no se han encontrado registros históricos. Para el sismo y tsunami asociado de 1906, solamente se ha encontrado el relato realizado por el fraile Antonio Corredor García, quien para la época era monje misionero en Tumaco y describe muy alegóricamente el comportamiento del evento desde el momento del sismo hasta el retroceso final de las olas (ver Anexos en Velasco, 2015). Del tsunami de 1942 no se han encontrado relatos. Para ambos casos los registros en los diarios colombianos no fueron hallados pues coincidencialmente en ambas fechas no se emitieron periódicos.

El sismo y tsunami de 1958 fue registrado por el diario El Tiempo, en cuya página principal expuso lo sucedido y desarrolló la noticia con las declaraciones del director del Instituto Geofísico de los Andes (Velasco, 2015). Para ésta época, el diario El Espectador no emitía frecuentemente.

En el año de 1979 los periódicos El Tiempo y El Espectador registraron con gran atención lo sucedido en la Costa Pacífica Colombiana, hablando inicialmente de al menos 200 muertos, 900 heridos y un número no conocido de desaparecidos, distribuidos principalmente en las costas de los departamentos de Nariño y Cauca (Velasco, 2015). No obstante, como se observa en la TABLA 1, las cifras fueron mucho mayores y quizás sub-estimadas por la difícil comunicación de la época. Es de destacar que el evento en mención arrasó por completo con las poblaciones de San Juan de la Costa y El Charco (Ramírez y Goberna, 1980). Posteriormente el evento fue descrito por varios autores (e.g. Ramírez y Goberna, 1980; Pararas-Carayannis, 1980; Herd et al., 1981), quienes además de dar datos de la afectación humana, hablaron del fenómeno geológico en sí.

En síntesis, los registros históricos afianzan la veracidad de la amenaza y el daño que se puede causar en cuanto a vidas humanas, sistemas económicos y sociales, de ahí la importancia que sean tomados como base fundamental para el desarrollo de estudios tsunamigénicos. Como ejemplo se tiene el Gran Terremoto de Hakuho en Japón, que fue el primer tsunami registrado históricamente el 29 de noviembre de 684 , y a partir del cual se buscaron evidencias sedimentológicas que comprobaran su existencia (NOAA, 2015). Los registros históricos también ayudan a establecer una primera noción de la periodicidad histórica de eventos tsunamigénicos en una zona determinada, a la cual se le pueden sumar eventos ocurridos en tiempos pre-históricos, determinados por análisis geocronológicos de la evidencia física, conformando así una base de datos más completa y fundamental para establecer la recurrencia tsunamigénica para una región específica. 


\section{DISCUSIÓN: AMENAZA Y VULNERABILIDAD EN EL PACÍFICO COLOMBIANO}

Es indiscutible la existencia de la amenaza por tsunamis en el Pacífico colombiano. La subducción en el norte de la placa de Nazca es activa, a una velocidad de 4,5 $\mathrm{cm} / a n ̃ o$, siendo una zona propicia para la generación de tsunamis. No obstante, el conocimiento de la morfología, flexibilidad y dinámica de la zona de subducción es aún limitado, desconociéndose así características más específicas de esta fuente cercana en cuanto a su potencial de generación de tsunamis, a diferencia por ejemplo de su homónimo en el Pacífico Canada-EE.UU, Cascadia.

Investigaciones específicas referentes a las fuentes regionales y lejanas generadoras de tsunamis para el Pacífico colombiano, no han sido caracterizadas aún, sin embargo deben ser tenidas en cuenta en el marco para estudios tsunamigénicos en el país, ya que fenómenos naturales de este tipo no conocen fronteras sociopolíticas o culturales.

Como se observó antes, morfológicamente el $75 \%$ de la costa pacífica está representada por bajos topográficos susceptibles a inundaciones de origen marino. Algunos municipios como Tumaco, Guapi, Buenaventura y Bahía Solano, entre otros, están construidos sobre dichos terrenos (FIGURAS 4 y 5), siendo altamente susceptibles a nuevas inundaciones, licuefacción del suelo, subsidencia regional, entre otros, que al igual que en 1906 y 1979 podrían llegar a tener consecuencias catastróficas para dichas comunidades en caso de un tsunami.

Para el caso específico de cuantificar el riesgo por tsunami, determinar el tipo de construcción y su extensión superficial es un elemento clave en el análisis de la vulnerabilidad. Las construcciones livianas de poca resistencia a impactos mecánicos, como es el caso de las estructuras palafíticas en Tumaco, son altamente susceptibles al ser derrumbadas por fenómenos de tsunami, además de convertirse rápidamente en escombros que se suman a la masa de agua, actuando como elementos cortantes y contundentes para la integridad física de las personas.

Con respecto a la propagación e inundación de tsunamis, no se pueden olvidar los avances realizados en el modelamiento numérico de la inundación, tal como se puede ver en la FIGURA 6 (Sánchez et al.,
2013) en el que se muestran dos escenarios básicos (teniendo en cuenta la topografía y el nivel del mar en la región): zonas de inundación por tsunami en marea baja y en marea alta. Actualmente, la única herramienta de gestión del riesgo frente a eventos de tsunami en la región sur del Pacífico colombiano (específicamente la Bahía de Tumaco) es el mapa de inundación por modelamiento numérico realizado Sánchez et al. (2013). Sin embargo, es preciso que se desarrollen trabajos que los complementen, usando evidencias geológicas y geomorfológicas que brinden bases sólidas y mejoren los escenarios propuestos. Es allí donde la investigación de paleo-tsunamis juega un papel fundamental, pues a partir de su correcta identificación y ubicación en el sub-suelo, fuera de verificar su real extensión lateral y alcance topográfico y altitudinal en el terreno, se pueden obtener todos los datos necesarios para delimitar las zonas exactas de inundación pasadas por paleo-tsunamis, validando y/o corrigiendo así el modelo computacional de inundación teórica, si este existe para la región afectada. La sedimentología, paleontología, y geoquímica, entre otras herramientas (TABLA 2), son imprescindibles para caracterizar e identificar correctamente cualquier paleo-tsunami. A su vez, la datación numérica (precisa y exacta) de dichos paleo-tsunamis nos ayudarían a determinar la frecuencia de ocurrencia de estos fenómenos, generando conocimiento y argumentos sólidos como base de las decisiones que permitan minimizar la vulnerabilidad y el riesgo de las zonas costeras estudiadas.

El Pacífico colombiano es rico en zonas de manglar, las cuales coinciden con costas morfológicamente bajas, asociadas a islas barrera, costas lodosas, sistemas deltaicos y playas (FIGURA 4). En el marco tsunamigénico, dicha correlación es importante pues aunque las zonas planas y bajas son fácilmente inundadas en eventos de tsunami, la presencia de vegetación como manglares representa una barrera natural eficaz frente al evento. Para la costa pacífica nariñense (FIGURA 5) se observa la presencia de manglares que igualmente hacen suponer un escenario de protección frente a eventos de tsunami. Se observan también las zonas de mayor exposición a erosión costera causada por las trayectorias de los trenes de oleaje, aunque las trayectorias graficadas correspondan al promedio de la región, éstas zonas están expuestas a erosión constante, potencialmente dificultando la conservación del sedimento depositado en caso de un tsunami, elemento a tener en cuenta en la búsqueda de evidencia física en esta región. 
Si bien existen varias investigaciones antropológicas y arqueológicas para la Costa Pacífica Colombiana, no se han encontrado relaciones específicas entre los efectos de fenómenos pasados como tsunamis o tormentas, que hayan cambiado la dinámica socio-cultural o causado la extinción de comunidades indígenas y/o afroamericanas, i.e. aun no se conoce la verdadera razón de la extinción de la cultura Tumaco - La Tolita en la región costera de Nariño; o no se conocen simbolismos representativos del fenómeno de tsunami descrito por nuestros antepasados, algo relativamente común en otras sociedades ancestrales del mundo. A pesar de no encontrarse más registros históricos que los eventos tsunamigénicos nombrados, u otros eventos que aún no se han detectado, esto no significa que los tsunamis no existan en nuestros mitos, leyendas o tradiciones orales, por lo que deben seguirse buscando en los registros históricos.

\section{RECOMENDACIONES Y CONCLUSIONES}

Es necesario desarrollar trabajos en tectónica de subducción, geomorfología marina, modelos de generación y propagación de tsunamis, y en general de caracterización de fuentes tsunamigénicas regionales y cercanas, que permitan conocer la verdadera magnitud de la amenaza por tsunami en el Pacífico colombiano.

Igualmente se deben realizar investigaciones históricas, antropológicas, biológicas y geológicas que muestren la existencia o no de paleo-tsunamis a lo largo de la Costa Pacífica Colombiana, con el rigor y esmero que se requiere, sobre todo en cuanto a la caracterización, identificación y ubicación geográfica de la evidencia física encontrada en el terreno, para así poder determinar con exactitud la extensión y alcance reales de eventos de tsunamis pasados, y así corroborar, verificar y corregir cualquier modelo computacional existente, tanto de inundación como de propagación de tsunamis para una región costera específica. Adicionalmente, es imprescindible ubicar todos los depósitos de tsunami encontrados en el terreno en el tiempo geológico mediante técnicas radiométricas numéricas de datación del Cuaternario, como lo son por ejemplo, OSL, ${ }^{14} \mathrm{C}$, entre otros. Trabajos de esta evidencia física de tsunamis deben estar soportados por mapas de facies marinas que muestren el tipo de sedimentos existentes en la plataforma, con el fin de conocer el tipo de material que estará presente en los depósitos de tsunami.
Cualquier investigación que se desarrolle en torno a evidencia física de paleo-tsunamis en las zonas inter-tropicales y ecuatoriales es novedosa y de gran importancia por la carencia de estas a nivel mundial. Las dificultades y obstáculos existentes en la Región Ecuatorial - inter-tropical no son comunes en mayores latitudes, por lo que no se sabe con exactitud qué aspectos de la evidencia física dejada por tsunamis van a estar comprometidos por la existencia de procesos, a veces severos, autóctonos y comunes en estas zonas como la alta humedad, escorrentía, pluviosidad, meteorización, degradación, formación de suelo, alta generación de materia orgánica, vegetación extrema, etc. Fuera de ser estudios imprescindibles para las comunidades poblando estas bajas latitudes a nivel mundial.

Estudios de geomorfología costera, subsidencia sedimentaria y/o tectónica, suelos, aceleración sísmica local, vegetación costerae identificación de las condiciones habitacionales de las comunidades ancestrales, deben ser generados con el ánimo de conocer la dinámica ambiental de una zona y el grado de vulnerabilidad de una comunidad, para así poder comprender mejor el riesgo al cual esta está sometida en la eventualidad de un tsunami.

Se debe verificar la capacidad de resistencia de manglares y su potencial de uso como barreras naturales de mitigación frente a tsunamis, al igual que estimular la cultura de su siembra, cuidado y conservación en comunidades costeras a través de buenas campañas de educación social ligadas a la prevención de desastres naturales.

En resumen, para efectuar investigaciones paleotsunamigénicas en el Pacífico colombiano, o cualquier otra región ya que los pasos y factores serían similares, se recomienda seguir los pasos detallados en la FIGURA 8, la cual puede considerarse como la metodología científica a seguir para la realización adecuada de investigaciones en paleo-tsunamis. Además, se recomienda que todos los resultados obtenidos mediante la realización de dichos pasos sean integrados en un solo mapa de amenaza por tsunami, cuya finalidad mayor es el beneficio de la comunidad, y que por ende, sirva como base sólida a la gestión del riesgo, así como sugerido en DOGAMI (2012). La elaboración de este tipo de trabajos, resultados y conclusiones y más aún su aplicación, se verán reflejadas directamente en la reducción de la vulnerabilidad de las comunidades costeras frente a fenómenos tan ineludibles como los de tsunami. 


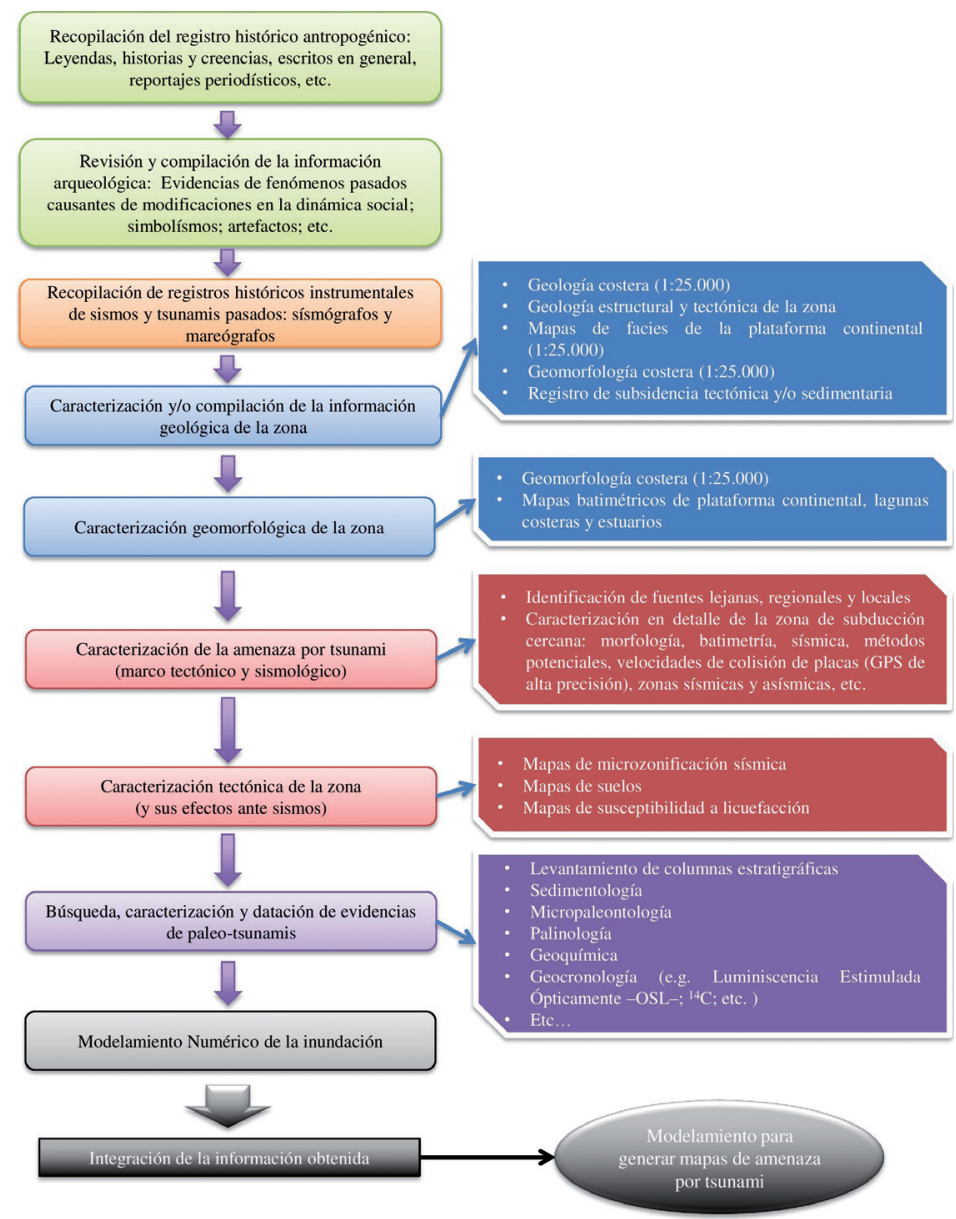

FIGURA 8. Secuencia sugerida para la realización de mapas de amenaza por tsunami. A la izquierda se encuentran las etapas principales de investigación y a la derecha el procedimiento a llevar a cabo para cada una de estas.

\section{AGRADECIMIENTOS}

Los autores agradecen a la DIMAR-CCCP por su apoyo, soporte e interés en el marco de conceptualización de esta investigación, su activa colaboración durante la visita a sus instalaciones en Tumaco, y su gentil invitación a la Primera Reunión Ordinaria Anual del Comité Técnico Nacional de Alerta por Tsunami (17-18 Marzo 2015). Igualmente, los autores agradecen a las siguientes instituciones, sin orden específico, por su apoyo e interés en el desarrollo de proyectos de investigación de esta índole en el país: el Servicio Geológico Colombiano SGC (Dirección de Geoamenazas), la Universidad Nacional de Colombia (Sede Tumaco), la Dirección del CEPREVÉ - Universidad Nacional de Colombia (Sede Bogotá), la Alcaldía de Tumaco, la Cruz Roja Colombiana (Unidad Municipal Tumaco), la Unidad Nacional para la Gestión del Riesgo de Desastres UNGRD (Dirección Nacional y Comité Municipal Tumaco), líderes comunales y rescatistas de diversas cabeceras municipales y caseríos costeros Nariñenses, el
Instituto Colombiano de Antropología e Historia ICANH (Coordinación Grupo de Arqueología), la Universidad del Cauca (Profesor Diógenes Patiño, Departamento de Antropología), el Laboratorio Geológico GMAS (Bogotá), la Universidad de Caldas (Instituto de Investigaciones en Estratigrafía IIES) y la Universidad EAFIT (Sede Medellín; Departamento de Geología). Este manuscrito fue elaborado dentro del marco de concepción de una propuesta de investigación científica sobre paleo-tsunamis para el Pacífico Colombiano, ideada y liderada por GIL. Los autores expresan sinceros agradecimientos a Myriam C. López Cardona y un evaluador anónimo por la revisión del manuscrito, sus valiosos comentarios y aportes constructivos, los cuales permitieron mejorar su estructura y versión final.

\section{REFERENCIAS}

Alongi, D.M. 2008. Mangrove forests: Resilience, protection from tsunamis, and responses to global climate change. Estuarine, Coastal and Shelf Science, 76: 1-13. 
Atwater, B.F., Musumi-Rokkaku, S., Satake, K., Tsuji, Y., Ueda, K., and Yamaguchi, D.K. 2005. The Orphan Tsunami of 1700 - Japanese clues to a parent earthquake in North America. U.S. Geological Survey Professional Paper, 1707: 144.

Atwater, B.F., Nelson, A.R., Clague, J.J., Carver, G.A., Yamaguchi, D.K., Bobrowsky, P.T., Bourgeois, J., Darienzo, M.E., Grant, W.C., Hemphill-Haley, E., Kelsey, H.M., Jacoby, G.C., Nishenko, S.P., Palmer, S.P., Peterson, C.D., and Reinhart, M.A. 1995. Summary of coastal geologic evidence for past Great Earthquakes at the Cascadia Subduction Zone. Earthquake Spectra 11: 1-18.

Atwater, B.F., ten Brink, U., Buckley, M., Halley, R.S., Jaffe, B.E., López-Venegas, A.M., Reinhardt, E.G., Tuttle, M.P., Watt, S., and Wei, Y. 2011. Geomorphic and stratigraphic evidence for an unusual tsunami or storm a few centuries ago at Anegada, British Virgin Islands. Natural Hazards, 63: 51-83.

Barbier, E.B. 2008. In the wake of tsunami: Lessons learned from the household decision to replant mangroves in Thailand. Resource and Energy Economics. 30: 229-249.

Barrero, D., Pardo, A., Vargas, C.A., and Martinez, J.F. 2007. Colombian Sedimentary Basins: Nomenclature, boundaries and petroleum geology, a new proposal. ANH \& B\&M Exploration Ltda. Bogotá, 92p.

Bastidas, M., y Puentes, M. G. 2008. Estimación del riesgo por tsunami de origen cercano en la bahía de Buenaventura (Informe Final). Centro de Investigaciones Oceanográficas e Hidrográficas del Pacífico (CIOH). San Andrés de Tumaco, 43p.

Betania, M. 1964. Mitos, leyendas y costumbres de las tribus sudamericanas. Editorial Coculsa. Madrid, 248p.

Borrero, C., Pardo, A., Jaramillo, C.M., Osorio, J.A., Cardona, A., Flores, A., Echeverri, S., Rosero, S., García, J., and Castillo, H. 2012. Tectonostratigraphy of the Cenozoic Tumaco forearc basin (Colombian Pacific) and its relationship with the northern Andes orogenic build up. Journal of South American Earth Sciences, 39: 75-92.

Borrero, J.C., and Goring, D.G. 2015. South American tsunamis in Lyttelton Harbor, New Zealand. Pure and Applied Geophysics, 172: 757-772.

Bouchard, J.F. 1989. Relaciones interculturales en el área ecuatorial del Pacifico durante la época precolombina.
IntenationaI Congress of Americanists, Amsterdam, Holanda, pp. 46.

Bryant, E. 2010. Tsunami, the underrated hazard. 2nd Edition. Springer, Chichester, 367p.

Caballero, L., y Ortiz, M. 2003. Evaluación del impacto de tsunamis en el litoral pacífico colombiano. Parte II (Región Buenaventura). Boletín Científico CCCP, 9: 45-57.

Cardona, Y. 2004. Análisis del arribo de ondas de tsunami a las poblaciones de la Bahía de Tumaco a través de señales sintéticas. Boletín Científico CCCP, 11: 42-49.

Cardona, Y. 2005. Modelación de tsunamis en la costa pacífica colombiana caso de aplicación Bahía de Tumaco. Tesis de Grado. Universidad Nacional de Colombia, Escuela de Geociencias y Medio Ambiente, Medellín. 123p.

Cediel, F., Restrepo, I., Marín-Cerón, M.I., DuqueCaro, H., Cuartas, C., Mora, C., Montenegro, G., García, E., Tovar, D. and Muñoz, G. 2010. Geology and hydrocarbon potential Atrato and San Juan Basins, Chocó (Panamá) Arc, Colombia; Tumaco Basin (Pacific Realm). Fondo Editorial EAFIT - ANH, Medellín, $178 \mathrm{p}$.

Chagué-Goff, C., Schneider, J., Goff, J., DomineyHowes, D., and Strotz, L. 2011. Expanding the proxy toolkit to help identify past events - Lessons from the 2004 Indian Ocean Tsunami and the 2009 South Pacific Tsunami. Earth-Science Reviews, 107: 107-122.

Chiarabba, C., De Gori, P., Faccenna, C., Speranza, F., Seccia, D., Dionicio, V., and Prieto, G. 2015. Subduction system and flat slab beneath the Eastern Cordillera of Colombia. Geochem. Geophys. Geosyst., 17: 16-27.

Chunga, K., y Quiñónez, M.F. 2013. Evidencia sedimentaria de tsunamis en la planicie aluvial de Villamil Playas, Golfo de Guayaquil. Acta Oceanográfica del Pacífico, 18: 163-180.

Chunga, K., and Toulkeridis, T. 2014. First evidence of paleo-tsunami deposits of a major historic event in Ecuador. Science of Tsunami Hazards, 33: 55-69.

Cisternas, M., Atwater, B.F., Torrejón, F., Sawai, Y., Machuca, G., Lagos, M., Eipert, A., Youlton, C., Salgado, I., Kamataki, T., Shishikura, M., Rajendran, C.P., Malik, 
J.K., Rizal, Y., and Husni, M. 2005. Predecessors of the giant 1960 Chile earthquake. Nature, 437: 404-407.

CIOH. 2005. Atlas cartográfico de los océanos y costas de Colombia. Publicación No. 3007-2, Bogotá D.C., $83 p$.

Clague, J.J., and Bobrowsky, P.T. 1999. The geological signature of great earthquakes on Canada's west coast. Geoscience Canada, 26:1-15.

Clague, J.J., Bobrowsky, P.T., and Hamilton, T.S. 1994. A sand sheet deposited by the 1964 Alaska tsunami at Port Alberni, British Columbia. Estuarine, Coastal and Shelf Science, 38(4):413-421.

Clague, J.J., Bobrowsky, P.T., and Hutchinson, I. 2000. A review of geological records of large tsunamis at Vancouver Island, British Columbia, and implications for hazard. Quaternary Science Reviews, 19:849-863.

Contreras-López, M. 2014. Riesgo de tsunami en Ecuador. Ingenius, 12: 68-75.

DIMAR-CCCP. 2013. Estudio de la Amenaza por Tsunami y Gestión del Riesgo en el Litoral Pacífico Colombiano, Serie Publicaciones Especiales Vol. 8. Dirección General Marítima - Centro de Investigaciones Oceanográficas e Hidrográficas del Pacífico. San Andrés de Tumaco, pp, 129.

De Gracia, C., O'dea, A., Rodríguez, F., y D'croz, L. 2012. Respuesta ambiental en el Pacífico frente a la subducción de la dorsal asísmica de Cocos (Panamá y Costa Rica). Revista de Biologia Tropical, 60: 893-908.

DNP. 1997. Los pueblos indígenas de Colombia Desarrollo y Territorio. Departamento Nacional de Planeación en codirección con TM editores. Bogotá D.C., pp. 126-127.

DOGAMI. 2012. Tsunami Inundation Maps (TIM) Series. Consultado el 15 de mayo de 2015. http://www. oregongeology.org/pubs/tim/p-TIM-Coos-05.htm

Dumont, J.F., Santana, E., Valdez, F., Tihay, J.P., Usselmann, P., Iturralde, D. and Navarrete, E. 2006. Fan beheading and drainage diversion as evidence of a 3200-2800 BP earthquake event in the Esmeraldas - Tumaco seismic zone: A case study for the effects of great subduction earthquakes. Geomorphology, $74: 100-123$.
Duque-Caro, H. 1990. The Chocó Block in the northwestern corner of South America: structural, tectonostratigraphic, and paleogeographic implications. Journal of South American Earth Sciences, 3:71-84.

Esquivel, I.P. 2006. Estimación del impacto en la hidrodinámica y la calidad del agua por la regeneración de la antigua isla barrera "El Guano" como elemento protector de Tumaco ante tsunamis mediante la aplicación de modelos numéricos. Tesis de Grado. Universidad de La Salle, Facultad de Ingeniería Ambiental y Sanitaria, Bogotá D.C. 162p.

Farreras, S.F., Domínguez, R., y Gutiérrez, C.A. 2005. Tsunamis: Serie - Fascículos. Centro Nacional de Prevención de Desastres, Mexico D.F., 44p.

Goff, J., Chagué-Goff, C., Nichol, S., Jaffe, B., and Dominey-Howes, D. 2012. Progress in palaeotsunami research. Sedimentary Geology, 243(244):70-88.

Goff, J.R., and Mcfadgen, B.G. 2001. Nationwide tsunami during prehistoric Maori occupation, New Zealand. The Twentieth International Tsunami Symposium, Seattle, U.S.A., pp. 469-476.

González, C. 2003. Cambios en la vegetación y el clima durante los últimos 40.000 años en la cuenca de Panamá, Pacífico Colombiano: Evidencia palinológica de secciones marinas ODP 677B y TR 163-38. Simposio Forestal DCF, Medellín, Colombia, pp. $1-200$.

González, F., y Sánchez, M.C. 2011. Evaluación de la amenaza por tsunami. Tesis de Grado. Universidad Javeriana, Facultad de Ingeniería, Departamento de Ingeniería Civil, Bogotá D.C. 233p.

González, J.L., and Correa, I.D. 2001. Late Holocene evidence of coseismic subsidence on the San Juan Delta, Pacific Coast of Colombia. Journal of Coastal Research, 17(2): 459-467.

Gonzalez, J.L., Shen, Z., and Mauz, B. 2014. New constraints on Holocene uplift rates for the Baudo Mountain Range, northwestern Colombia. Journal of South American Earth Sciences, (52): 194-202.

Herd, D., Youd, L., Meyer, H., Arango, J.L., Person, W.J., and Mendoza, C. 1981. The Great Tumaco Earthquake of 12 December 1979. Science, 211(4481): 441-445. 
Husen, S., Kissling, E., and Quintero, R. 2002. Tomographic evidence for a subducted sea- mount beneath the Gulf of Nicoya, Costa Rica: the cause of the $1990 \mathrm{Mw}=7.0$ Gulf of Nicoya earthquake. Geophysical Research Letters, 29: 791-794.

Hutchinson, I., and Mcmillan, A.D. 1997. Archaeological evidence for village abandonment associated with Late Holocene earthquakes at the northern Cascadia Subduction Zone. Quaternary Research, 48: 79-87.

IGAC 2005. Mapa físico - político de Colombia, versión digital. Escala gráfica. Instituto Geográfico Agustín Codazzi. Bogotá D.C.

IGAC e INGEOMINAS. 2008. Investigación integral del andén Pacífico Colombiano, Tomo II - Geomorfología. IGAC. Bogotá D.C., 205p.

ITIC. 2015. International Tsunami Information Center: Tsunami Glossary. Consultado el 30 de abril de 2015. http://itic.ioc-unesco.org/index.php?option $=$ com_conte nt\&view $=$ article \&id=1868\&Itemid $=2306$

Kathiresan, K., and Rajendran, N. 2005. Coastal mangrove forests mitigated tsunami. Estuarine, Coastal and Shelf Science, 65: 601-606.

Keigwin, L.D. 1978. Pliocene closing of the Isthmus of Panama, based on biostratigraphic evidence from nearby Pacific Ocean and Caribbean Sea cores. Geology, 6: 630-634.

Keller, G., Zenker, C.E., and Stone, S.M. 1989. Late Neogene history of the Pacific- Caribbean gateway. Journal of South American Earth Sciences, 2: 73-108.

Kellogg, J., and Vega, V. 1995. Tectonic development of Panama, Costa Rica and the Colombian Andes: constraints from global positioning system geodetic studies and gravity. Geological Society of America, 295: 75-90.

Kodaira, S., Takahashi, N., Nakanishi, A., Miura, S., and Kaneda, Y. 2000. Subducted sea- mount imaged in the rupture zone of the 1946 Nankaido earthquake. Science, 289: 104-106.

Kopp, H. 2013. Invited review paper: The control of subduction zone structural complexity and geometry on margin segmentation and seismicity. Tectonophysics, 589: 1-16.
Lagos, M. 2000. Tsunamis de origen cercano a las costas de Chile. Revista de Geografía Norte Grande, 27: 93-102.

Lim, S., Ledru, M.-P., Valdez, F., Devillers, B., Houngnon, A., Favier, C., and Bremond, L. 2013. Ecological effects of natural hazards and human activities on the Ecuadorian Pacific coast during the late Holocene. Palaeogeography, Palaeoclimatology, Palaeoecology, 415: 197-209.

Lonsdale, P., and Klitgord, K.D. 1978. Structure and tectonic history of the eastern Panama Basin. Geological Society of America Bulletin, 89: 981-999.

López, G.I. 2012. Evidence for mid- to late-Holocene palaeotsunami deposits, Kakawis Lake, Vancouver Island, British Columbia. Natural Hazards, 60: 43-68.

López, G.I. and Bobrowsky, P.T. 2001. A 14000 year-old-record from a coastal freshwater lake: Sedimentological evidence for tsunamigenic events on the west coast of Vancouver Island, British Columbia, Canada. International Tsunami Symposium, Vol. 3(3 -4), Seattle, U.S.A., pp. 491-500.

Macinnes, B.T., Bourgeois, J., Pinegina, T.K., and Kravchunovskaya, E. A. 2009. Tsunami geomorphology: Erosion and deposition from the 15 November 2006 Kuril Island tsunami. Geology, 37: 995-998.

Martínez, J., Rodríguez, O., y Robertson, K. 2005. Amenazas naturales en el litoral Pacífico Colombiano asociadas al ascenso del nivel del mar. Cuadernos de Geografía, 14: 83-96.

Martínez, J.O., and López, E. 2011. High-resolution seismic stratigraphy of the late Neogene of the central sector of the Colombian Pacific continental shelf: A seismic expression of an active continental margin. Journal of South American Earth Sciences, 31: 28-44.

Maya, L.A. 2003. Atlas de las Culturas Afrocolombianas, Capítulo de Habitad y Arquitectura. Ministerio de Educación Nacional. Bogotá D.C., 49p.

McCalpin, J.P. 2009. Paleoseismology. International Geophysics Series, 2nd Edition. Academic Press, Burlington, U.S.A., 802p.

Meschede, M., and Brackhausen, U. 2000. Plate tectonic evolution of the Cocos - Nazca spreading center. Procedings of the Ocean Drilling Program, Scientific Results, 170: 1-10. 
Molina,A.,y Mirmand,L. 1992. Estudio sedimentológico de la plataforma continental norpacífica Colombiana (Bahía de Buenaventura - frontera con Panamá). Boletín Científico CIOH, 10: 27- 36.

Morton, R.A., Gonzalez, J.L., López, G.I., and Correa, I.D. 2000. Frecuent non-storm washover of barrier islands, Pacific Coast of Colombia. Journal of Coastal Research, 16: 82-87.

Morton, R.A., González, J.L., Correa, I.D., Salazar, O., Tabares, N., y López, G.I. 2002. Causas y efectos de eventos atípicos de sobre-lavado en la Costa Pacíica de Colombia - los eventos de sobre-lavado de mayo a agosto de 1997 en la Isla El Choncho, Delta del Río San Juan. En: Geología y oceanografía del Delta del Río San Juan (Litoral Pacífico Colombiano) (Correa, I.D. y Restrepo, J.D., eds.). Universidad EAFIT COLCIENCIAS, Medellín, pp. 133-150.

Morton, R.A., Gelfenbaum, G., and Jaffe, B.E. 2007. Physical criteria for distinguishing sandy tsunami and storm deposits using modern examples. Sedimentary Geology, 200: 184-207.

Moziño, J.M. 1792. Noticias de Nutka (An account of Nootka Sound in 1792). American Ethnological Society Monograph 50: 142.

NGDC. 2015. National Geophysical Data Center Tsunami Database. Consultado el 10 de mayo de 2015. https://www.ngdc.noaa.gov

NGDC. 2000. National Geophysical Data Center - Tsunami Database: Tsunami Event Database and Tsunami Run-up Database. Consultado el 9 de mayo de 2015. http:// www.ngdc.noaa.gov/seg/hazard/

NOAA. 2015. National Geophysical Data Center / World Data Service (NGDC/WDS): Global Historical Tsunami Database. Consultado el 10 de mayo de 2015. http://www.ngdc.noaa.gov/hazard/tsu_db.shtml

OSSO. 1992. Aproximación al riesgo por tsunami en la costa del pacífico en Colombia. Publicaciones Ocasionales del OSSO, 2: 1-44.

Otero, L.J., González, M. y Olabarrieta, M. 2013. Avances en la investigación de la amenaza por tsunami en zonas costeras. En: Estudio de la Amenaza por Tsunami y Gestión del Riesgo en el Litoral Pacífico Colombiano (DIMAR-CCCP Ed.). DIMAR, San Andrés de Tumaco, pp. 11-30.
Page, W., and James, M. 1981. Tectonic subsidence and evidence for the recurrence of large magnitude earthquakes near Bahia Solano, Colombia. Tercer Congreso Colombiano de Geología, Bogotá D.C., Colombia, pp. 19.

Pararas - Carayannis, G. 1980. El terremoto y el tsunami de 12 de diciembre de 1979 en Colombia: extractos de una encuesta emprendida de Diciembre 20, 1979 al Enero 5, 1980, en Colombia y Ecuador. En: Informe Comisión Oceanográfica Intergubernamental y al Grupo de Coordinación Internacional para el sistema Amonestador de Tsunami en el Pacifico (ICG/ITSU Ed.). ICG/ITSU. pp. 15-33.

Patiño, D. 1988. Orfebreria Prehispanica en la Costa Pacífica de Colombia y Ecuador: "Tumaco - La Tolita". Boletín del Museo del Oro, 22: 17-31.

Patiño, D. 1992. Sociedades Tumaco - La Tolita: Costa Pacífica de Colombia y Ecuador. Boletín de Arqueología, 7:37-49.

Patiño, D. 1993. Arqueología del Bajo Patía, fases y correlaciones en la Costa Pacífica de Colombia y Ecuador. Latin American Antiquity, 4: 180-199.

Patiño, D. 2003a. Campos prehispánicos elevados en la economía Tumaco-tolita, Costa pacífica de Colombia. Universidad del Cauca. Popayán, 92p.

Patiño, D. 2003b. Tumaco Prehispánico: asentamiento, subsistencia e intercambio en la Costa Pacífica de Colombia. Universidad del Cauca. Popayán, 259p.

Peralta, H., Arellano, J., Leusson, A., Quiñones, J., Camacho, R., Llanos, L., y Mendoza, J. 2003. Evaluación de la vulnerabilidad física por terremoto y sus fenómenos asociados en poblaciones del Litoral de Nariño. Congreso de Ingeniería Sísmica, Bogotá D.C., Colombia, pp. 44-53.

Pilarczyk, J.E., and Reinhardt, E.G. 2011. Homotrema rubrum (Lamark) taphonomy as an overwash indicator in Marine Ponds on Anegada, British Virgin Islands. Natural Hazards, 63: 85-100.

Posada, B.O., Henao, W., y Guzmán, G. 2009. Diagnóstico de la erosión y sedimentación en la zona costera del Pacífico Colombiano. INVEMAR, Serie de Publicaciones Especiales, Santa Marta, 117p. 
Prendergast, A.L., Cupper, M.L., Jankaew, K., and Sawai, Y. 2012. Indian Ocean tsunami recurrence from optical dating of tsunami sand sheets. Marine Geology, 295-298: 20-27.

Quiñónez, H. 2011. Aumento de las viviendas palafíticas sobre bienes de uso público en Tumaco. En: DIMAR. Archivo de noticias, impacto de actividades antrópicas en áreas marinas y costeras. Dirección General Marítima, San Andrés de Tumaco, pp. 42-65.

Ramírez-Herrera, M.T. 2011. Evidencias ambientales de cambios de nivel de la costa del Pacífico de México: Terremotos y tsunamis 1. Revista de Geografia Norte Grande, 124: 99-124.

Ramírez-Herrera, M.T., Lagos, M., Hutchinson, I., Kostoglodov, V., Machain, M.L., Caballero, M., Goguitchaichvili, A., Aguilar, B., Chagué-Goff, C., Goff, J., Ruiz-Fernández, A.C., Ortiz, M., Nava, H., Bautista, F., Lopez, G.I., and Quintana, P. 2012. Extreme wave deposits on the Pacific coast of Mexico: Tsunamis or storms? - A multi-proxy approach. Geomorphology, 139(140): 360-371.

Ramírez-Herrera, M.T., Bógalo, M.F., Cerny, J., Goguitchaichvili, A., Corona, N., Machain, M.L., Carranza Edwards, A., and Sosa, S. 2016. Historic and ancient tsunamis uncovered on the JaliscoColima Pacific coast, the Mexican subduction zone. Geomorphology, 259: 90-104.

Ramírez, J.E., y Goberna, J.R. 1980. Terremotos colombianos noviembre 23 y diciembre 12 de 1979. Publicación del Instituto Geofísico de los Andes Colombianos, Serie A: Sismología, 45: 1-28.

Ramos, V. 2010. The Grenville-age basement of the Andes. Journal of South American Earth Sciences, 29: 77-91.

Reinhardt, E.G., Goodman, B.N., Boyce, J.I., Lopez, G., Van Hengstum, P., Rink, W.J., Mart, Y., and Raban, A. 2006. The tsunami of 13 December A.D. 115 and the destruction of Herod the Great's harbor at Caesarea Maritima, Israel. Geology, 34: 1061-1064.

Reinhardt. E.G., Nairn, R.B., and López, G.I. 2010. Recovery estimates for the Río Cruces after the may 1960 Chilean earthquake. Marine Geology, 269: 18-33.

Restrepo, H.A. 1971. Zona de falla de Puerto Mutis en Bahía Solano - El terremoto de Bahía Solano del 26 de Septiembre de 1970. Publicación serie A Instituto Geofísico de los Andes Colombianos, Sismología, 33: 27-34.

Restrepo, J.C., y Otero, L.J. 2007. Modelación numérica de eventos tsunamigénicos en la Cuenca Pacífica Colombiana - Bahía de Buenaventura. Revista Academia Colombiana de Ciencias, 31(120): 363-377.

Restrepo, J.D., and Kjerfve, B. 2002. The San Juan Delta, tides, circulations, and salt dispersión. Continental Shelf Research, 22: 1249-1267.

Sánchez, J. 2012. Caracterización y diagnóstico socioeconómico y ambiental de la Costa Pacífica en el departamento de Nariño. Servicio Nacional de Aprendizaje (SENA). Bogotá D.C., 118 p.

Sánchez, R.E, Otero, L.J., y De La Rosa, R. 2013. Modelado numérico de tsunamis: Caso de estudio. En: Estudio de la Amenaza por Tsunami y Gestión del Riesgo en el Litoral Pacífico Colombiano (DIMARCCCP Eds.). DIMAR, San Andrés de Tumaco, pp. 5170.

Satake, K., Shimazaki, K., Yoshinobu, T., and Ueda, K. 1996. Time and size of a giant earthquake in Cascadia inferred from Japanese tsunami records of January 1700. Nature, 379: 246-249.

Shiki, T., and Yamazaki, T. 2008. The term "Tsunamiite". En Tsunamiites: Features and Implications (Shiki, T, Tsuji, Y., Yamazaki, T. y Minoura, K., Eds.). Elsevier, UK, pp. 5-7.

Shuto, N., and Fujima, K. 2009. A short history of tsunami research and countermeasures in Japan. Proceedings of the Japan Academy. Series B, Physical and biological sciences, 85: 267-275.

Soloviev, S.L., and Go, C.N. 1974. A catalogue of tsunamis on the western shore of the Pacific Ocean (173-1968). Nauka Publishing House, 310p.

Steer, R., Ramos, A., Enríquez, F., y García, M. 2008. Amenaza de desastres: Construcciones palafíticas sobre bienes de uso público. Procuraduría General de la Nación, Bogotá D.C. 501pp.

Sugawara, D., Minoura, K., and Imamura, F. 2008. Tsunamis and tsunami sedimentology. En Tsunamiites: Features and Implications (Shiki, T, Tsuji, Y., Yamazaki, T. y Minoura, K., Eds.). Elsevier, UK, pp. 9-45. 
Sun, W., Huang, R., Li, H., Hu, Y., Zhang, C., Sun, S., Zhang, L., Ding, X., Li, C., Zartman, R., and Ling, M. 2015. Porphyry deposits and oxidized magmas. Ore Geology Reviews, 65: 97-131.

Taboada, A., Dimaté, C., y Fuenzalida, A. 1998. Sismotectónica de Colombia: deformación continental activa y subducción. Física de la Tierra, 10: 111-147.

Taboada, A., Rivera, L., Fuenzalida, A., Cisternas, A., Philip, H., Bijwaard, H., Olaya, J., and Rivera, C. 2000. Geodynamics of the northern Andes: Subductions and intracontinental deformation (Colombia). Tectonics, 19: 787-813.

Trenkamp, R., Kellogg, J.N., Freymueller, J.T., and Mora, H.P. 2002. Wide plate margin deformation, southern Central America and northwestern South America, CASA GPS observations. Journal of South American Earth Sciences, 15: 157-171.

Urrego, L.E., y Ramírez, L.F. 1999. Cambios en la vegetación durante el holoceno reciente en el delta del río San Juan, Pacífico Colombiano. Tesis de Grado. Universidad Nacional de Colombia, Departamento de Ciencias Forestales, Medellín, 72p.

Velasco, E.R. 2015. Marco conceptual para estudios tsunamigénicos en el Pacífico Colombiano. Tesis de Grado. Universidad Nacional de Colombia, Departamento de Geo-ciencias, Facultad de Ciencias, Bogotá D.C., 66p.

Vargas, C. A, Mann, P., and Borrero, C. 2011. Field guides for excursions to the Nevado del Ruiz Volcano and to the Romeral Fault System (Colombia ), in the frame of the Neotectonics of arc-continent collision concepts. Earth Sciences, 15: 47-74.

Vargas, C. A., and Mann, P. 2013. Tearing and breaking off of subducted slabs as the result of collision of the Panama arc-indenter with Northwestern South America. Bulletin of the Seismological Society of America, 103: 2025-2046.

Villagómez, D., Spikings, R., Magna, T., Kammer, A., Winkler, W., and Beltrán, A. 2011. Geochronology, geochemistry and tectonic evolution of the Western and Central cordilleras of Colombia. Lithos, 125: 875 - 896.

Von Huene, R., Miller, J.J., and Weinbrebe, R.W. 2012. Subducting plate geology in three great earthquake ruptures of the western Alaska margin, Kodiak to Unimak. Geosphere, 8.
Wadge, G., and Burke, K. 1983. Neogene Caribbean plate rotation and associated Central American tectonic evolution. Tectonics, 2: 633-643.

Trabajo recibido: noviembre 23 de 2015 Trabajo aceptado: julio 15 de 2016 Manuscrito publicado en internet: agosto 24 de 2016 